\title{
Zur Entwicklung der jungquartären Tieflandstäler im Saale-Elbe-Raum unter besonderer Berücksichtigung von ${ }^{14} \mathrm{C}$-Daten
}

\author{
Achim Hiller, Thomas Litt \& Lothar Eissmann *)
}

Late Quaternary, fluvial environment, Weichselian low terrace, Holocene floodplain, gravel, floodloam, subfossil wood, radiocarbon data, human impact

Saale-Elbe region, Weiße Elster River, Mulde River

Kurzfassung: Erstmalig wurden für den Saale-Elbe-Raum - als geologisch gut erschlossenes Untersuchungsgebiet Mitteleuropas - systematisch gesammelte Proben durch Radiokarbon datiert. Somit ist es möglich, das weichselzeitliche Alter der intakten und gekappten Niederterrasse zu bestätigen sowie die stark differenzierte holozäne Flußdynamik chronostratigraphisch zu erfassen. Die in der nacheiszeitlichen Flußgeschichte innerhalb eines komplexen Wirkungsgefüges ablaufenden Sedimentationsprozesse wurden in bestimmten Einzugsgebieten durch mittelbare anthropogene Eingriffe bereits seit neolithischer Zeit stark beeinflußt. Dies zeigt sich vor allem im Beginn und Verlauf der Auelehmakkumulation. Durch die radiometrische Datierung subfossiler Hölzer aus holozänen Flußschottern konnte ebenfalls für den mitteldeutschen Raum die Verdrängung der Kiefer durch die Eiche aus den Flußtälern bereits für das Boreal (ältestes ${ }^{14} \mathrm{C}$-Datum $8790 \pm 140 \mathrm{BP}$ ) festgestellt werden. Dies stimmt gut mit Befunden aus anderen Flußgebieten vor allem des südlichen Mitteleuropas überein.

\section{[On the development of the Late Quaternary river valleys in the Saale-Elbe lowland with emphasis on radiocarbon data]}

Abstract: Radiocarbon dating has been applied for the first time to samples systematically collected in the Saale-Elbe area, a well geologized region in Central Europe, in order to enable precise statements to be made on how the valleys were formed during the Late Quaternary. Hence, it is possible to confirm the Weichselian age of the intact and the reduced low terrace and to record chronostratigraphically the greatly differentiated fluvial dynamics during the Holocene. The sedimentation processes taking place within a complex

*) Anschrift der Verfasser: Dr. A. Hiller, Zentralinstitut für Isotopen- und Strahlenforschung, Permoserstr. 15, 7050 Leipzig. Dr. T. LITT, WB Geologische Wissenschaften der Martin-Luther-Universität, Domstr. 5, 4020 Halle/Saale. Dr. L. EISSMANN, WB Geophysik der Universität Leipzig, Talstr. 35, 7010 Leipzig. structure of activity during the postglacial history of the fluvial environment were strongly influenced by immediate anthropogenic interferences in defined catchment areas already since the Neolithic period. This becomes evident, above all, from the way how the flood loam accumulation started and took its course. By method of radiometric dating the subfossil woods from Holocene gravels it was possible to establish - also for the Central German region - that the pine was displaced by the oak from the river valleys as early as during the Boreal (oldest radiocarbon date $8790 \pm 140$ $\mathrm{BP}$ ). This agrees well with findings from other river areas, especially of southern Central Europe.

\section{Inhalt}

1 Einleitung

2 Methodische Bemerkungen zu den Radiokohlenstoffanalysen

3 Zur Morphologie und zum allgemeinen geologischen Aufbau der Tieflandstäler

4 Die Ausbildung der Niederterrasse

5 Spät- und nacheiszeitliche Flußtalentwicklung 6 Schriftenverzeichnis

\section{Einleitung}

Die alte Wahrheit, daß die wirklichen Probleme beim Angehen des Details beginnen, bestätigt in beredter Weise die Erforschung unserer Tieflandstäler. Auf vielen älteren, aber auch jüngeren geologischen Karten erscheinen sie als wenig differenzierte, breite, oft allein nach morphologischen Kriterien dargestellte Einheiten. Die Auflösung der komplexen sichtbaren und verborgenen Sedimentfolge war und ist durch viele Faktoren erschwert: Die Aufschlußdichte ist vielfach gering, auch größere Aufschlüsse (Kiesgruben) gewähren durch hohe Grundwasserstände oft 
nur geringen Einblick in die Abfolgen und schließlich sind die Sedimente arm an Unterscheidungsmerkmalen. Früher standen der Analyse gewisse allgemeine Kenntnislücken im Wege, vor allem zur Sedimentologie, Flußdynamik, Klimatologie und Archäologie (Besiedlung der Einzugsgebiete, der Niederungen selbst etc.). Nicht zuletzt wirkten sich der Mangel an relativen und, bis in die 50er Jahre hinein, auch an absoluten Alterswerten nachteilig aus.

Sieht man das schwache Fundament, auf dem früher Forschung getrieben werden mußte, wird verständlich, daß man in den sächsischen Flußniederungen selbst 20 und mehr Meter mächtige Sedimentfolgen kurzerhand in das Holozän einordnete, fast alles grobe rollige Material über dem Tertiär.

Extreme Gegenansichten wollten später eigentlich nur noch den Auelehm als ein holozänes Sediment gelten lassen und alles grobe fluviatile Material darunter in die Weichselzeit und in ältere Kaltzeiten einstufen.

In den letzten Jahrzehnten ergaben sich durch Tausende von Bohrungen und den Braunkohlenbergbau für das sächsische und angrenzende Tiefland im Flußgebiet der Weißen Elster/Pleiße, der Mulde und Elbe aus der Sicht der Aufschlüsse nahezu optimale Bedingungen für die Erforschung der Täler und ihrer Sedimentfolgen. Elster-, Pleiße- und Muldetal (vgl. Abb. 2) wurden an verschiedenen Stellen in ihre ganzen Breite bis tief in die Tertiärfolge durchschnitten.

Die Forschungskapazität reichte bisher nicht aus, alle Beobachtungen festzuhalten und auf ihre Ursachen hin zu untersuchen. Zeitweise kamen Unmengen an fossilen Baumstämmen in den Tagebauen ans Licht, meist von Eichen. Die Funde drängten nach ${ }^{14} \mathrm{C}$ Datierungen, die in größerem Umfang erst in den 80er Jahren möglich wurden.

In dieser Publikation sollen aus der Sicht der Autoren die Hauptbefunde vorgestellt werden ${ }^{1}$ ). Sie verdeutlichen, daß die in den Tälern verborgenen Sedimentabfolgen sehr heterogen sind und selbst in geringer Tiefe unter den Auen liegende Schichten unterschiedlichen Zeitabschnitten angehören können, was Verwechslungen in bezug auf Zeit und Herkunft des Schichtmaterials Tür und Tor öffnet.

Wir wollen uns auf den Abschnitt Weichseleiszeit bis Gegenwart begrenzen, doch sollen die Abbildungen,

1) Die holzanatomischen Bestimmungen wurden in dankenswerter Weise von Herrn Dr. C. SCHIRAREND (Museum für Naturkunde Berlin) durchgeführt. Danken möchten wir ebenfalls den Herren Geol.-Ing. R. WIMMER, Dipl.-Geol. K. PARDEYKe und Dipl.-Geol. J. VÖLKE, die uns bei der Zusammenstellung des Probenmaterials unterstützten. vor allem die synoptischen, die Vielfalt der Geologie der Täler deutlich machen. Uns scheint, daß die Befunde Modellcharakter für den ganzen Übergangsbereich vom Norddeutsch-Polnischen Tiefland zu den Hügelländern besitzen. Wohl reizen die Befunde zu Vergleichen mit anderen großen Flußgebieten, aus Zeit- und Platzgründen haben wir uns diesen weitgehend versagt, nicht ohne die Hoffnung, dies später nachzuholen.

\section{Methodische Bemerkungen zu den Radiokohlenstoffanalysen}

Die Vorbehandlung von Holz hat die Anreicherung der Zellulose zum Ziel, die für Kohlenstoffisotopenanalysen am besten geeignet ist (STUIVER 1978). In Anlehnung an Vorschriften von BANNISTER \& DAMON (1972) und DE JONG \& MOOK (1980) wurden in der Regel 25-50 g zerkleinertes Holzmaterial mit $1 \mathrm{M}$ $\mathrm{HCl}$ und $0,5 \mathrm{M} \mathrm{NaOH}$ extrahiert, wobei evtl. anhaftende Carbonatbestandteile, Lignin, Harze, Pektine weitgehend gespalten und herausgelöst werden.

Bei torfhaltigen Sedimenten erfolgte die Vorbehandlung nach Aussieben und/oder Aufschlämmen zur Anreicherung der organischen Bestandteile im allgemeinen in ähnlicher Weise. Durch die $\mathrm{NaOH}-\mathrm{Be}$ handlung werden Huminsäuren in eine lösliche Form überführt. Dies ist insofern wichtig, da Huminsäuren in Böden relativ mobil und möglicherweise allochthonen Ursprungs sind, woraus eine Altersverfälschung resultieren kann. Bei einigen dieser Proben mußte allerdings wegen der geringen Anteile an organischer Substanz auf eine alkalische Extraktion verzichtet werden.

Torfhaltige Sedimente wurden in einem System zweier Quarzrohre im Sauerstoffstrom nach DE VRIES zu $\mathrm{CO}_{2}$ verbrannt und in üblicher Weise in Benzen überführt. Ein $\mathrm{CO}_{2}$-Aliquot wurde zur massenspektrometrischen C-13-Analyse entnommen. Die ${ }^{13} \mathrm{C}$-Isotopenzusammensetzung wird als $\% 00$-Abweichung vom PDB-Standard angegeben.

Die meisten Holzproben wurden nach einem seltener praktizierten Verfahren in $\mathrm{Li}_{2} \mathrm{C}_{2}$ überführt (vgl. StARIK, ARSLANOV \& KLEINER 1963; SWART 1964). Der einzige Nachteil dieser Methode besteht darin, daß keine ${ }^{13} \mathrm{C}$-Bestimmungen für das $\mathrm{Holz}$ möglich sind, sondern nur $\delta^{13} \mathrm{C}$-Werte des Pyrolyse- $\mathrm{CO}_{2}$ erhalten werden. Obwohl die Kenntnis des genauen $\delta^{13} \mathrm{C}$-Wertes nur für ${ }^{14} \mathrm{C}$-Präzisionsanalysen bei dendrochronologischen Kalibrierungen von Bedeutung ist, wurde bei einigen Proben versucht, durch Bestimmung der ${ }^{13} \mathrm{C}$-Gehalte der einzelnen $\mathrm{CO}_{2}$-Fraktionen charakteristische Parameter abzuleiten, um aus dem 
experimentell bestimmten $\delta^{13} \mathrm{C}$-Wert des Pyrolyse$\mathrm{CO}_{2}$ auf $\delta^{13} \mathrm{C}$ des Gesamtholzes schließen zu können. Es ergab sich angenähert: $\delta^{13} \mathrm{C}=\delta^{13} \mathrm{C}$ (Pyrolyse- $\left.\mathrm{CO}_{2}\right)$ $-1,7 \%$.

Die ${ }^{14} \mathrm{C}$-Aktivitätsmessung wurde mit Hilfe der Flüssigkeitsszintillationsspektrometrie durchgeführt. Die konventionellen ${ }^{14} \mathrm{C}$-Alter sind hinsichtlich der Isotopenfraktionierung auf der Grundlage experimentell bestimmter oder berechneter $\delta^{13} \mathrm{C}$-Werte auf $-25 \%$ normalisiert und mit der Libby-Halbwertzeit $(\tau 1 / 2$ : 5568 Jahre) berechnet unter Bezugnahme auf das Jahr 1950. Die angegebenen Standardabweichungen ( $1 \sigma)$ enthalten den berechneten zählstatistischen Fehler sowie andere experimentelle Unsicherheiten. Alle diese Daten sind in Tab. 1 zusammengefaßt.

Die dendrochronologisch kalibrierten Altersbereiche fossiler Hölzer wurden auf Grundlage der verfügbaren Kalibrierungskurven und -tabellen sowie weiterer Kalibrierungsdaten ermittelt (STUIVER \& PEARSON 1986).

Bei 9 Holzproben wurden Doppelanalysen durchgeführt, die - bis auf GOI 8 und 12 - im Rahmen des $1 \sigma$-Fehlers gut übereinstimmende ${ }^{14} \mathrm{C}$-Alter ergaben.

Die Vertrauenswürdigkeit der radiometrischen ${ }^{14} \mathrm{C}$ Alter ist unterschiedlich zu bewerten. Während Holz als zu datierendes Material meist zuverlässige Alter liefert, unterliegen torfhaltige Ablagerungen weitaus häufiger Kontaminationseffekten durch allochthonen Kohlenstoff (Huminsäureinfiltration, anthropogene Einflüsse, Durchwurzelung u. a.), die selten quantitativ beseitigt werden können. Kontaminationseffekte führen vor allem bei hohen ${ }^{14} \mathrm{C}$-Altern zu deutlichen Abweichungen. So ergibt eine 40000 Jahre alte Probe bei einer angenommenen Kontamination mit $2 \%$ fossilem Kohlenstoff - unabhängig vom Probenalter - ein um nur 160 Jahre zu hohes scheinbares ${ }^{14} \mathrm{C}$-Alter. Dagegen bewirkt $2 \%$ ige Rezentkontamination ein um ca. 11000 Jahre kleineres scheinbares ${ }^{14} \mathrm{C}$-Alter! Demzufolge ist es ratsam, derart große ${ }^{14} \mathrm{C}$-Alterswerte von Torf, Mudde etc. als Minimalalter zu betrachten.

\section{Zur Morphologie und zum allgemeinen geologischen Aufbau der Tieflandstäler}

Die sächsischen und angrenzenden Tieflandstäler der Elbe und ihrer Nebenflüsse sind teils mit hoher und steiler Geländestufe von den meist aus Grundmoränen-Sand / Kies-Wechsellagerungen aufgebauten Hochflächen abgesetzt, teils gehen sie stufenlos ineinander über, so daß es bei Geländestudien schwerfällt, eine Grenze zu ziehen. Das vielleicht beste
Beispiel auf engem Raum liefert das Tal der Weißen Elster, wo sich südlich von Groitzsch die Hochfläche mauerartig vom Tal absetzt, jedoch nördlich der Lößrandstufe von Pegau, etwa bei dem ehemaligen Ort Eythra, der Übergang kilometerweit nahezu stufenlos vollzieht. Im Elbegebiet hebt sich unterhalb von Torgau die Hochfläche mit oft steilem Rand von der Talaue $a b$, im E dagegen existiert weithin ein völlig kontinuierlicher Übergang.

Die Bildung der jungen Täler, die bei der Mulde und der Weißen Elster über lange Strecken einen wesentlich anderen Verlauf aufweisen als im Mittel- und Altquartär, erfolgte vornehmlich in der Zeit des Saaleeiszerfalls bis in die Eemwarmzeit. Seither ist die fluviatile Eintiefung nicht wesentlich weitergekommen.

Innerhalb der in die elster- und saaleeiszeitlichen Moränenplatten bzw. saalespätglazialen Urstromtalbildungen (Elbegebiet) eingeschnittenen (postdrenthezeitlichen) Talzüge lassen sich drei fluviatile bzw. fluviatil-glazifluviatile Sedimentkomplexe unterscheiden:

- die Obere oder Höhere Niederterrasse

- die Untere Niederterrasse oder allgemein: Niederterrasse

— die Talaue mit Niederterrasseninseln.

Sehr ausgeprägt ist diese Konfiguration im Muldegebiet zwischen Wurzen und Eilenburg (vgl. Abb. 2). Auf die im ganzen wenig scharf von der saaleeiszeitlichen Moränenhochfläche abgesetzten, zur „Höheren Niederterrasse" zusammengefaßten Platte um + $125 \mathrm{~m} \mathrm{NN}$ (bei Wurzen) folgt die Platte der Unteren Niederterrasse (nördlich von Wurzen um $+115 \mathrm{~m}$ $\mathrm{NN}$ ) und nach einer ca. $5 \mathrm{~m}$ hohen Geländestufe die Talaue (ca. $110 \mathrm{~m} \mathrm{NN}$ ) mit flachen Niederterrasseninseln.

Letztere sind gegenüber der Aue leicht erhöhte Flächen mit hochliegenden Schottern, die meist nicht von Auenlehm, sondern sog. Tallehm überzogen sind. GrahmanN (1924) sah in ihnen Reste seiner ,jüngstdiluvialen Talterrasse". Wir sehen in ihnen pfeilerartig stehengebliebene, erniedrigte Teile der Niederterrasse. Bei dem hangenden Lehm von wenigen Dezimeter Mächtigkeit handelt es sich um ein dem Auelehm nicht unähnliches Umlagerungssubstrat, vorwiegend wohl aus Löß- und Hanglehm.

Da die Vertretungen der "höheren Niederterrasse” hier nicht weiter behandelt werden sollen, sie aber in der gegenwärtigen Diskussion um die Gliederung des sog. Saalekomplexes eine gewisse Rolle spielen (FUHRMANN 1976, 1989), seien dazu einige Bemerkungen gemacht. 
In der „Höheren Niederterrasse” werden Sande und Kiese zusammengefaßt, die dort, wo die Untere Niederterrasse deutlich aushaltbar ist wie bei Wurzen, terrassenartig über ihr liegen und den Eindruck erwecken, als seien sie erst nach Beginn der saaleglazialen Deglaziation abgelagert worden. Naheliegenderweise wurden diese Ablagerungen bisher gern dem „Warthestadial” zugeordnet, von FUHRMANN (1976, 1989) auch anderen Abschnitten des Saaleglazials.

Neuere Untersuchungen zeigen, daß es sich bei den Ablagerungen dieser vermeintlichen Terrasse um genetisch und stratigraphisch heterogene Sedimente handelt. Zunächst fällt auf, daß sie keinen durchlaufenden, sondern im Gegenteil einen häufig unterbrochenen Zug bilden. Oft sind es nur kleine unzusammenhängende Körper, vergleichbar sehr alten Schotterterrassenresten. Ganz im Gegensatz zur lithologisch einheitlichen Niederterrasse mit ihren für das jeweilige Einzugsgebiet typischen und damit unverkennbaren Schottergemeinschaften erwiesen sich die Reste in der Zusammensetzung als sehr wechselhaft. Unterhalb von Großbothen und speziell bei Grimma fehlt den Schottern an mehreren Stellen das Material der oberen Freiberger Mulde. Das ist nur verständlich, wenn es sich um wieder freigelegte Flußablagerungen aus der Elstereiszeit handelt, als die obere Freiberger Mulde noch direkt zur Elbe entwässerte. Doch existieren auch Schotterreste, die das ganze Muldeeinzugsgebiet vertreten. Der einzige wirklich zusammenhängende Zug an Ablagerungen mit Geröllen der Freiberger und Zwickauer Mulde liegt bei Wurzen (vgl. oben) und endet am sog. Thallwitzer Sporn. Soweit die wenigen Aufschlüsse einen Einblick in das Sediment gewähren, unterscheidet sich dieser Zug jedoch von den sonstigen Muldeablagerungen durch auffallend hohe Anteile an lokalen und nordischen Gesteinen. Wir sehen daher heute in diesen Ablagerungen talsanderartige Sedimente, die in der Zeit des Saaleeiszerfalls in Nordsachsen von in westliche Richtung abfließenden Schmelzwässern, beispielsweise aus dem Endmoränengebiet der Dahlener Heide, aufgeschüttet wurden, die sich um Wurzen mit Flußwässern der Mulde mischten.

Im heutigen Tal der Freiberger Mulde, beispielsweise im weiteren Stadtgebiet von Döbeln, existieren neben der sicheren Niederterrasse Schotterreste, die die Aue um 8 bis $12 \mathrm{~m}$ überragen (sog. $8 \mathrm{~m}$-Terrasse). Vor allem hangseitig können die Schotter von mächtigen Hanglehmen und Löß bedeckt sein. In Döbeln erweist sich der Löß durch einen kräftigen Pseudogleyboden, den FuHRMANN (1976) in die Eemwarmzeit stellt, als zweigeteilt.

FUHRMANN (1976) vermutet für die liegenden Schotter ein „flämingkaltzeitliches” Alter. Nach den
Revisionsarbeiten von WOLF (1978) bei Döbeln, durch die u. a. sedimentologisch die Lage der frühsaaleeiszeitlichen Hauptterrasse in der komplizierten Quartärfolge des Gebietes genauer ermittelt werden konnte, nämlich geodätisch wesentlich höher als bisher angenommen, halten wir die fraglichen Schotter für den Fuß der Hauptterrasse, also eine geschnittene Terrasse. Das erklärt auch den relativ hohen Verwitterungsgrad vieler Gerölle. Im Elbegebiet zwischen Riesa und Dessau-Coswig gibt es überhaupt keine Anzeichen für eine „Höhere Niederterrasse” (MÜLLER 1988). Doch existieren hier spätsaaleeiszeitliche Urstromtalbildungen, in die die Niederterrasse flach eingeschnitten ist. Mit diesen Darlegungen soll die Existenz von Flußschottern in der saaleeiszeitlichen Deglaziationsphase nicht grundsätzlich in Abrede gestellt werden. Sie bilden aber keinen zusammenhängenden, einheitlichen Terrassenkörper, sondern lediglich „Späne”.

Die entsprechenden Schotter verdanken ihre Aufschüttung lokalen kurzzeitigen Anhebungen der Erosionsbasis oder es sind Relikte der vom Fluß mitgeführten Geröllfracht, die bei der generellen Eintiefung am Talhang liegengeblieben, „übersprungen" worden sind.

Von den nach Beginn des Saaleeiszerfalls entstandenen Flußablagerungen besitzt einzig die Niederterrasse alle Attribute der älteren Flußterrassen, insbesondere der Frühelster- und Frühsaale- oder Hauptterrasse, wie durchlaufendes Profil, gleichsinniges Gefälle, absolute Vormacht von Gesteinen des Einzugsgebiets (,reine Flußschlotter”), Mächtigkeit, Korngrößenabnahme in der Vertikalen und eine breite Palette an Klimamarken.

Im Bereich der Tieflandsauen und der Niederterrassen des Untersuchungsgebiets erreichen an vielen Stellen die rolligen Flußsedimente Mächtigkeiten bis gegen 25 m. GRAHMANN (1925) vermutete als einer der ersten Forscher, daß es sich dabei nicht allein um Ablagerungen der Niederterrassenzeit und des Holozäns handeln dürfte. Die sehr differenzierten Geröllund Schwermineralgemeinschaften der sächsischen und thüringischen Flüsse und das vielfach strähnenartige vertikale Übereinander ihrer Schotterkörper im Gefolge mehrfacher Flußverlegungen im Quartär machten es relativ leicht, die GRAHMANNsche Ansicht zu bestätigen. Durch die Gunst der Aufschlüsse konnte bewiesen werden, daß sich in den Sedimentfolgen unter den jungen Talfüllungen Ablagerungen mehrerer Kaltzeiten verbergen, und daß ein im Mittel nur 10 bis $15 \mathrm{~m}$ mächtiger fluviatiler Sedimentkörper aus der Zeit der Weichseleiszeit und des Holozäns stammt. Den komplexen Aufbau der Sedimentfolgen unter den jungen Tälern veranschaulicht in ver- 


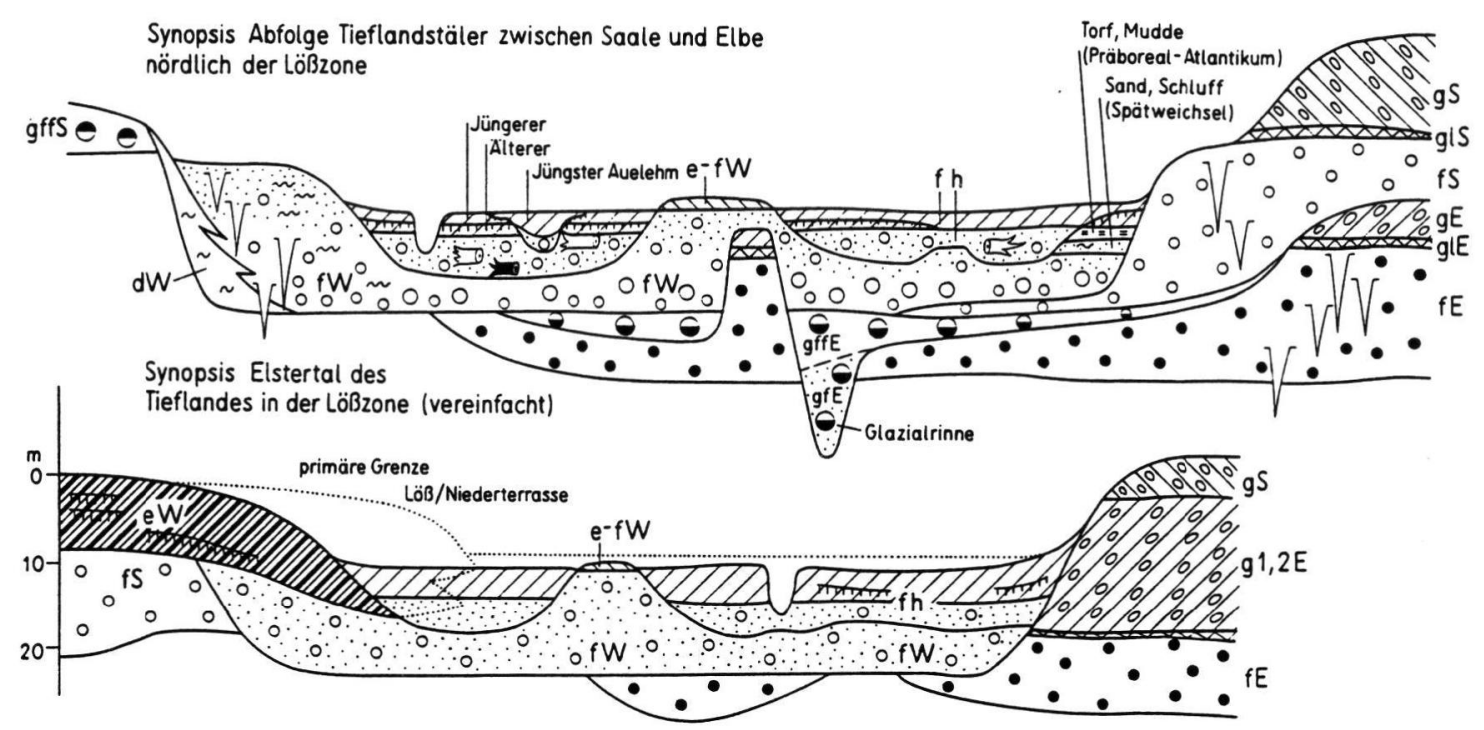

Abb. 1: Aus Tagebauaufnahmen und Bohrungen entworfene synoptische Schnitte durch die Sedimentfolgen der Tieflandstäler in der Leipziger Bucht sowie die liegenden und seitlich angrenzenden Quartärschichten (vereinfacht).

fh - fluviatiles Holozän (Auelehm und -schotter); e-fW - äolischer und fluviatiler Lehm (Tallehm) der Weichseleiszeit; $\mathrm{eW}$ - Lösse mit Bodenhorizonten do.; dW - deluvial-solifluidale Sedimente do.; fW - fluviatile Sedimente do (Niederterrasse); gffS - Mischschotter der Saaleeiszeit (lokal sog. Obere Niederterrasse); gS - ungeteilte Grundmoränen der Saaleeiszeit; gIS - Böhlener Bänderton do.; fS - fluviatile Sedimente do. (Haupt- oder Mittelterrasse);

$\mathrm{gE}, \mathrm{gl}, 2 \mathrm{E}$ - Grundmoränen und Zwischen- sowie Hangendsedimente der Elstereiszeit; $\mathrm{glE}$ - Dehlitz-Leipziger Bänderton, do.; $\mathrm{fE}$ - fluviatile Sedimente der frühen Elstereiszeit (ohne nordisches Material); gffE - Mischschotter der Elstereiszeit; gfE - glazifluviatile Sande und Kiese do.

dichteter Form die Abb. 1. Zwei Beispiele mögen die Gesamtsituation beleuchten. Der früher zeitweilig allein in das Holozän eingestufte Schotterkörper unter dem rezenten Talboden der Weißen Elster und Pleiße im weiteren Stadtgebiet von Leipzig besteht aus Ablagerungen der prä- und frühelstereiszeitlichen Saale, Weißen Elster, Wyhra und Zwickauer Mulde, der spätelstereiszeitlichen Mulde-Zschopau, der frühsaaleeiszeitlichen Vereinigten Mulde, Weißen Elster und Pleiße und schließlich der weichseleiszeitlichen und holozänen Weißen Elster und Pleiße.

In den Großaufschlüssen östlich von Bitterfeld (Tagebaue Goitsche und Rösa-Sausedlitz) ließen sich wiederum dank unverwechselbarer lithologischer Kriterien in den Talsedimentfolgen frühelstereiszeitliche (bedeckt lokal mit Bänderton und Elstergrundmoräne), spätelstereiszeitliche, weichseleiszeitliche und holozäne Schotter übereinander unterscheiden. Überall dort, wo die fluviatilen Abfolgen im Bereich der Täler nur aus einem einzigen Einzugsgebiet stammen, somit kaum lithologische Merkmale zur Trennung der einzelnen Aufschüttungskörper bestehen, kann daher die Gliederung der Sedimentfolgen der
Täler nur eine den tatsächlichen Verhältnissen grob angenäherte sein.

\section{Die Ausbildung der Niederterrasse}

Wie im vorangehenden Kapitel bereits ausgeführt, ist die Niederterrasse in den jungen, postdrenthezeitlichen Talzügen der einzige Schotterkörper, der in allen Merkmalen, vor allem Verbreitung, Mächtigkeit und lithologischer Ausbildung, der Frühelster- und Frühsaale- oder Hauptterrasse ähnelt. Wie jene die fluviatile Hauptfazies der Elster- und Saaleeiszeit vertreten, vertritt diese zweifelsfrei die der Weichseleiszeit.

Sowohl im Elbegebiet zwischen Riesa und Wittenberg und bei Dessau wie auch im Unterlauf der Mulde und Saale hebt sich die Niederterrasse mit einer bis maximal $6 \mathrm{~m}$, im Mittel 3 bis $4 \mathrm{~m}$ hohen Geländestufe deutlich von der Flußaue ab.

Der Schotterkörper besitzt eine mittlere Mächtigkeit von 8 bis $12 \mathrm{~m}$. Nach MÜLLER (1988) erreicht die 
Elbeniederterrasse im Gebiet von Riesa 13 bis $15 \mathrm{~m}$, bei Mühlberg und östlich von Torgau 15 bis $19 \mathrm{~m}$, um dann bis in die Gegend von Dessau auf 8 bis $11 \mathrm{~m}$ abzusinken. Das gibt das Bild eines periglaziären Schwemmkegels mit flußabwärts abnehmender Mächtigkeit und Korngröße. Die Ursachen dieser Schwemmfächerbildung sind u. a. die zeitweilige Überlastung des Flusses mit Frostschutt, nachlassende Wasserführung des Flusses im Verlauf des Weichselglazials und Gefälleverringung durch Laufverlängerung nach dem Saaleeiszerfall. Ausgeprägte Niederterrassenflächen sind auch bei der Mulde entwickelt. Lehrbuchartigen Charakter nehmen sie an zwischen Wurzen und dem Thallwitzer Vorsprung, flußrechtsseitig zwischen Eilenburg und Bad Düben und flußlinksseitig etwa zwischen Bad Düben und Bitterfeld, schließlich auch südöstlich von Dessau (Abb. 2). Südlich von Bad Düben werden Mächtigkeiten bis $20 \mathrm{~m}$, östlich von Bitterfeld bis $12 \mathrm{~m}$ erreicht. Im Gebiet der unteren Weißen Elster und Pleiße treten die Niederterrassenschotter morphologisch nur lokal in Erscheinung. Sie überragen die Aue maximal 2 bis $3 \mathrm{~m}$. Sie sind schwer von den Hauptterrassenkiesen abzutrennen, gegen die sie häufig stoßen. Niederterrasse und junge Talaue sind weithin nahezu deckungsgleich.

Das wesentliche Merkmal der Niederterrasse des Untersuchungsgebietes besteht in ihrer deutlichen vertikalen Korngrößenabnahme. In allen vollständigen Profilen lassen sich unterscheiden:

eine (obere) feine Folge

eine Übergangsfolge

eine (untere) grobe Folge.
Mitunter ist die Übergangsfolge sehr geringmächtig, so daß grobes fast unmittelbar gegen feines Material stößt und die Grenze in Schnitten oft viele kilometerweit in fast gleicher Höhe gezogen werden kann.

Die im Elbegebiet bisweilen 5-10 m mächtige grobe Folge besteht im großen und ganzen aus einem mittel- bis grobkörnigen, steinigen Kies, bisweilen jedoch auch aus überwiegend grobem Kies mit Steinen und Blöcken. Im Übergangsbereich wechseln Bänke aus Fein- bis Mittelkies mit solchen aus Mittelund Grobsand. In der im Elbegebiet 5 bis $10 \mathrm{~m}$, im Muldegebiet 3 bis $5 \mathrm{~m}$ mächtigen feinen Folge dominieren Mittel- bis Feinsand mit Grobsand- und Kiessandbänken, in denen der Korndurchmesser $12 \mathrm{~mm}$ kaum überschreitet. Unten überwiegt ein horizontales, im mittleren Abschnitt ein von wechselnder Schrägschichtung geprägtes und im oberen Teil wieder ein stärker horizontales Schüttungsgefüge (Abb. 3).

Die bei nahezu gleichbleibendem Gefälle in allen vollständigen Profilen beobachtbare Korngrößenabnahme kann nur mit zunehmender Aridisierung des Klimas erklärt werden. Im Laufe der Entwicklung ist mit einer Abflußverringerung von mehr als 50 Prozent zu rechnen. Am Ende der Akkumulation waren die Flüsse in dünne Rinnsale aufgelöst. Zwischen Falkenberg/Elster, Herzberg und Züllsdorf ist der Zustand der deltaartigen Zerteilung des Flusses in zahllose parallele Gerinne während der Schlußphase der Aufschotterung eindrucksvoll erhalten geblieben (MülLER 1988). Auch auf anderen Niederterrassen-

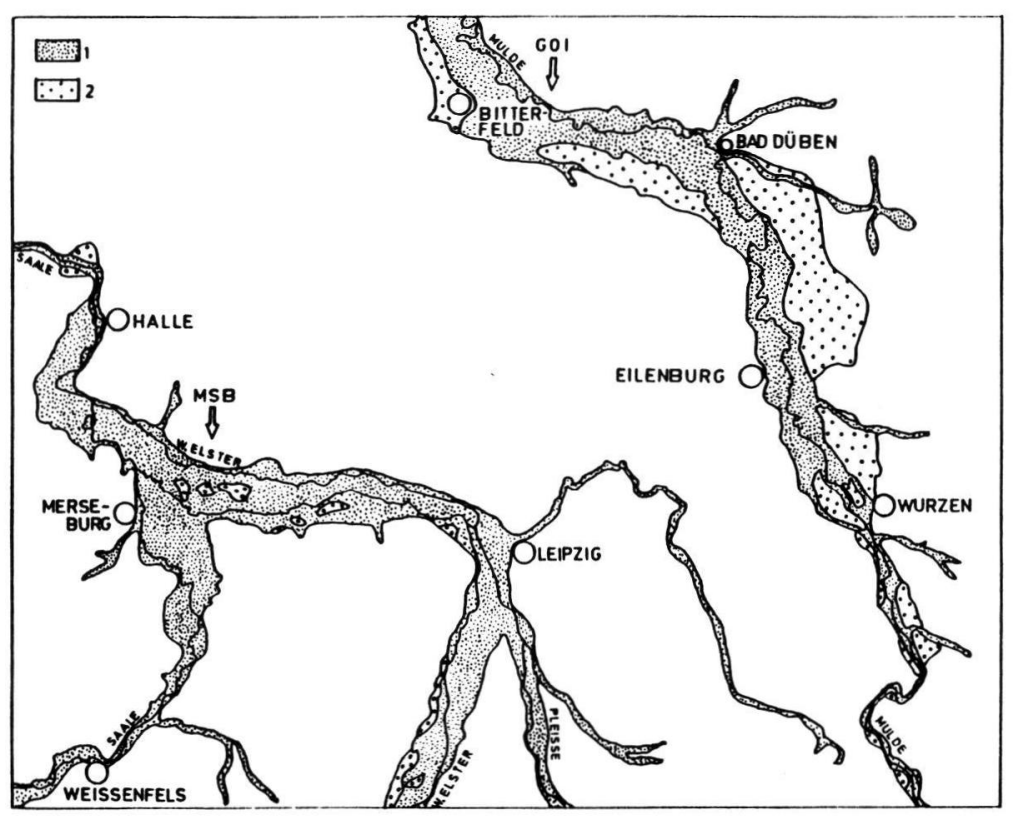

Abb. 2: Jungquartäre Flußtalkonfiguration in der Leipziger Bucht. 1 - Holozäne Talauen; 2 - weichselglaziale Niederterrassen; MSB - Tagebau Merseburg-Ost; GO I - Tagebaue Goitsche und Rösa. 

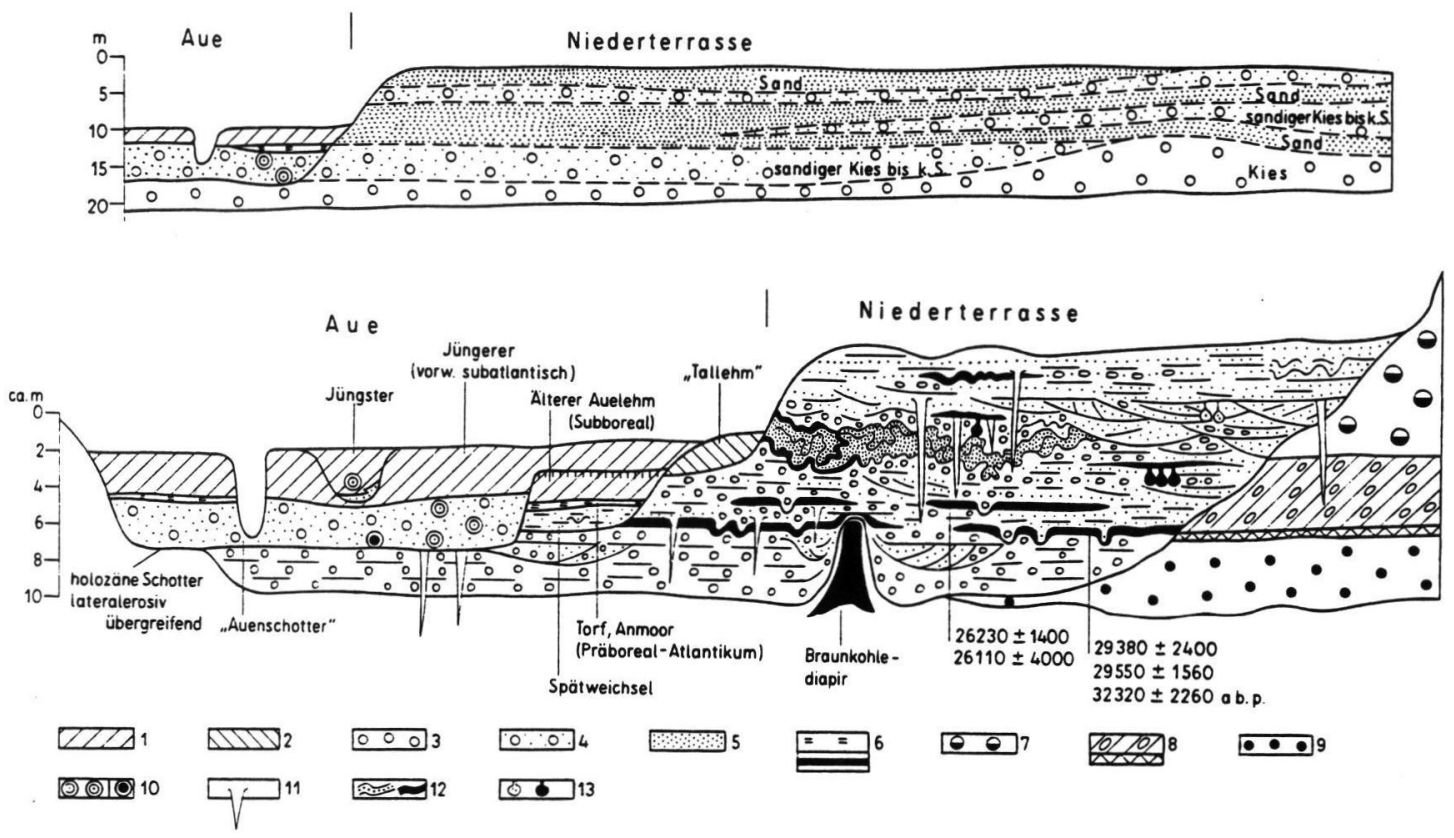

Abb. 3: Sedimentfolge und Morphologie der jungquartären Täler der nördlichen Leipziger Bucht nach Befunden aus Braunkohlentagebauen, Kiesgruben und Bohrungen.

Oben: nach Bohrungen rekonstruierter geologischer Schnitt durch die Muldenniederterrasse und -aue südlich von Bad Düben.

Unten: nach Tagebauaufnahmen und Bohrungen entworfener synoptischer Schnitt durch das Muldetal oberhalb von Bitterfeld.

1 - Auelehme; 2 - Tallehm (sandiger Schluff); 3 - vorherrschend Kies; 4 - Kies-Sand-Wechsellagerung bzw. kiesiger Sand; 5-vorherrschend Sand; 6 - Torf und stärker torfführend (oben) bzw. Mudden (unten); 7 - spätelsterzeitliche Mischschotter (sog. Krippehnaer Schotter); 8 - ungeteilte Elstergrundmoräne mit Dehlitz-Leipziger Bänderton an der Basis; 9- frühelstereiszeitliche Flußschotter der Saale / Weißen Elster; 10 - Baumstämme, links: überwiegend Eichen, rechts: Weichhölzer; 11 - Eiskeilpseudomorphosen; 12 - Brodelböden; 13 - Tropfenböden.

flächen kommt regional die Auflösung der Flüsse in einzelne Arme noch zum Ausdruck. Im Gegensatz zu den beiden nächst älteren Terrassen, bei denen durch die Inlandeisbedeckung die Akkumulation vor dem klimatisch gesteuerten Umbruch zum Wiedereinschnitt unterbrochen wurde, bilden die Niederterrassen des sächsischen Tieflandes das Musterbeispiel eines vom Frühglazial (Feuchtphase) bis zum Hochglazial (Trockenphase) aufgeschütteten Schotterkörpers.

Der Geröllbestand wechselt naturgemäß von Flußgebiet zu Flußgebiet. Im Bereich der Weißen Elster und Pleiße dominiert der Quarz, der 80 und mehr Prozent erreicht.

Die nachstehende Tabelle bringt zwei Einzelanalysen für die Elbe bei Torgau und die Mulde bei Bad Düben (Auszählungen vereinfacht nach A. MüLLER 1988 und
D. HÄNDEL (unveröff.)) der Kornfraktion 7 bis $15 \mathrm{~mm}$ (in Korn-\%).

Elbe Mulde
Quarzgruppe

Kristallin s. str.

Restkristallin

Quarzit, Schiefer, Grauwacke

Kieselschiefer

Porphyrgruppe

basische Effusiva

Feuerstein

Sonstige

$\begin{array}{rr}52,7 & 71,2 \\ 10,7 & 9,1 \\ 3,9 & \text { n. b. } \\ 15,2 & 5,7 \\ 5,7 & \text { n. b. } \\ 6,6 & 12,4 \\ 2,2 & 0,0 \\ 0,9 & 1,5 \\ 2,1 & 0,1\end{array}$

In allen Flußsystemen ist flußabwärts ein nennenswerter Anstieg des nordischen Anteils, vor allem gespiegelt im Feuerstein, festzustellen. Im Elbegebiet 
um Riesa bleibt der Feuersteingehalt meist unter $0,5 \%$, um Wittenberg liegt er bei $2 \%$.

Die Zufuhr von nordischem Material aus den beiderseits der Täler anstehenden Moränenmassen verwischt jedoch zumindest bis in den Raum Dessau das Typusbild der Geröllassoziationen der einzelnen Flüsse nicht. Das gilt auch für die Schwermineralgemeinschaft, die hier nicht weiter erörtert werden soll (MÜLLER et al. 1988). Die verwitterungs-empfindlichen Gerölle erweisen sich in den Niederterrassen als frisch, unter den Schwermineralen dominieren die instabilen Anteile. Zum Hangenden hin ist eine gewisse Zunahme von Gesteinsgrus in Form von Feldspat und Restkristallin aus Feldspat-Quarz-Glimmerverwachsungen u. a. zu beobachten als Ausdruck zunehmender Frostverwitterung. Die Niederterrasse ist reich an plastischen sowie rupturellen Sedimentdeformationen. Die plastischen Deformationen bezeugen mehrere Phasen hoher Sedimentlabilität, die rupturellen in Form von Frostrissen tiefe Bodengefrornis.

Die Frostrisse bestehen teils aus Pseudomorphosen echter Eiskeile, teils aus dünnen, d. h. nur Millimeter bis wenige Zentimeter breiten Spalten. Die ehemaligen Eiskeile sind ausschließlich mit Sanden und Kiesen gefüllt, im Mittel 0,2 bis $0,5 \mathrm{~m}$, maximal 1,5 bis $2 \mathrm{~m}$ breit und durchschnittlich 2 bis 4 , maximal 7 bis $8 \mathrm{~m}$ tief. In den Tagebauen Goitsche und MerseburgOst blieb der mittlere, auf Braunkohlenflözen im Liegenden der Schotter abgebildete Rißabstand lokal unter $50 \mathrm{~m}$. Stellenweise konnten auf $100 \mathrm{~m}$ Länge 15 bis 20 Risse beobachtet werden. Einige Rißstrukturen erreichten horizontale Längen von 100 bis knapp 300 m. Im Braunkohlentagebau Rösa-Sausedlitz östlich von Bitterfeld waren in der nahezu senkrechten Abbauwand zeitweilig mindestens bis zu sechs intraformationelle Rißgenerationen freigelegt (schematisch auf Abb. 3). Die parallelwandige symmetrische Auskleidung vieler dieser Strukturen ließ sie als Pseudomorphosen echter Eiskeile erkennen. Viele der Keile durchsanken die Schotter, drangen in das liegende Kohleflöz ein und geben sich dort als ein unregelmäßiges Netzwerk zu erkennen.

Je nach der Häufigkeit von Feinsand-, Schluff- und Muddeeinlagerungen ist die Niederterrasse durch gravitative plastisch bis rupturelle Sedimentdeformationen gestört.

Das Spektrum der Deformationen reicht von idealen Tropfenböden aus Feinsanden bis Schluffmudden über Girlandenstrukturen rasch wechselnder Wellenlänge und Amplitude der einzelnen Bögen bis zu regellosen Schlingen, Wülsten und isolierten Fetzen. Vielfach erweisen sich diese Strukturen als Belastungs- marken, entstanden in einer mobilen Phase bindiger Sedimente durch überlagernde Sande und Kiese. Gelegentlich kann ein Drittel bis zur Hälfte des Terrassenkörpers in der Vertikalen intensiv deformiert sein. Auf einigen Abschnitten der Niederterrasse bei Bitterfeld konnten vier bis sechs dieser „Kryoturbationshorizonte” übereinander festgestellt werden. Sie erwiesen sich vielfach als sichere intraformationelle Phänomene. Vor allem in der Anfangsphase der Schotterakkumulation kam es dort, wo die Terrassensedimente unmittelbar auf der Kohle liegen, verbreitet zu Diapirismus: Bei ungleicher Sedimentauflast wanderte die Braunkohle ab und drang diapirisch in die Schotter ein (Abb. 3). Der Vorgang ist mindestens bis in die Zeit um 30000 Jahre v. h. nachgewiesen, da eine entsprechende Zeitmarke im Tagebau Rösa-Sausedlitz vom Kohleaufstieg noch deformiert wurde.

Weit verbreitet ist auch die Erscheinung, daß Schotter gang- und nestartig in die liegende Braunkohle eindrang. Er folgte wahrscheinlich gravitativ austauendem Bodeneis in palsenartigen Strukturen, die sich zu Beginn der Niederterrassenzeit auf den Talböden entwickelt hatten. Alle diese Erscheinungen belegen die Existenz eines mächtigen Frostbodens und seines zeitweiligen Zerfalls bis in Tiefen vom Meter- bis Dekameterbereich, also der Bildung eines saisonalen und langzeitigen Mollisols.

Im Tiefland führt die Niederterrasse zahlreiche Einlagerungen von humosen Schluffen, Mudden, Torfmudden und lokal auch Torfen. Es konnten bisweilen vier bis sechs solcher Horizonte übereinander beobachtet werden. Die zwischen 2 und $12 \mathrm{~m}$ unter der Schotteroberkante entnommenen und untersuchten Proben ergaben im Pollenbestand keine wesentlichen Unterschiede.

Die Baumpollen sind sowohl im Anteil an der Gesamtsumme der terrestrischen Pflanzen als auch in der Artenzahl relativ gering vertreten (Pinus zwischen $15-35 \%$, Betula zwischen $2-17 \%$, Alnus bis $3 \%$ ). Eine größere Rolle spielen die Nichtbaumpollen, wobei besonders Artemisia (bis $24 \%$ ) als Heliophyt auf größere Offenlandflächen hindeutet. Die Zusammensetzung läßt generell auf subarktische bis arktische Klimabedingungen schließen, womit die Hauptfaunavertreter Mammut, Wollhaarnashorn und Moschusochse, nicht zuletzt die zahlreich beschriebenen Klimamarken aufs beste übereinstimmen. Da Reste der kälteresistenten Säuger bereits im Basisbereich auftreten und zwei der pollenanalytisch untersuchten Proben rund 2 bis $4 \mathrm{~m}$ über Schotterbasis liegen, darf für die gesamte Akkumulationszeit das kühle bis kalte, von kurzen relativen Erwärmungsphasen unterbrochene Klima angenommen werden. 
Tabelle 1: ${ }^{14} \mathrm{C}$-Datierungsergebnisse subfossiler Hölzer (und organischer Substanz)

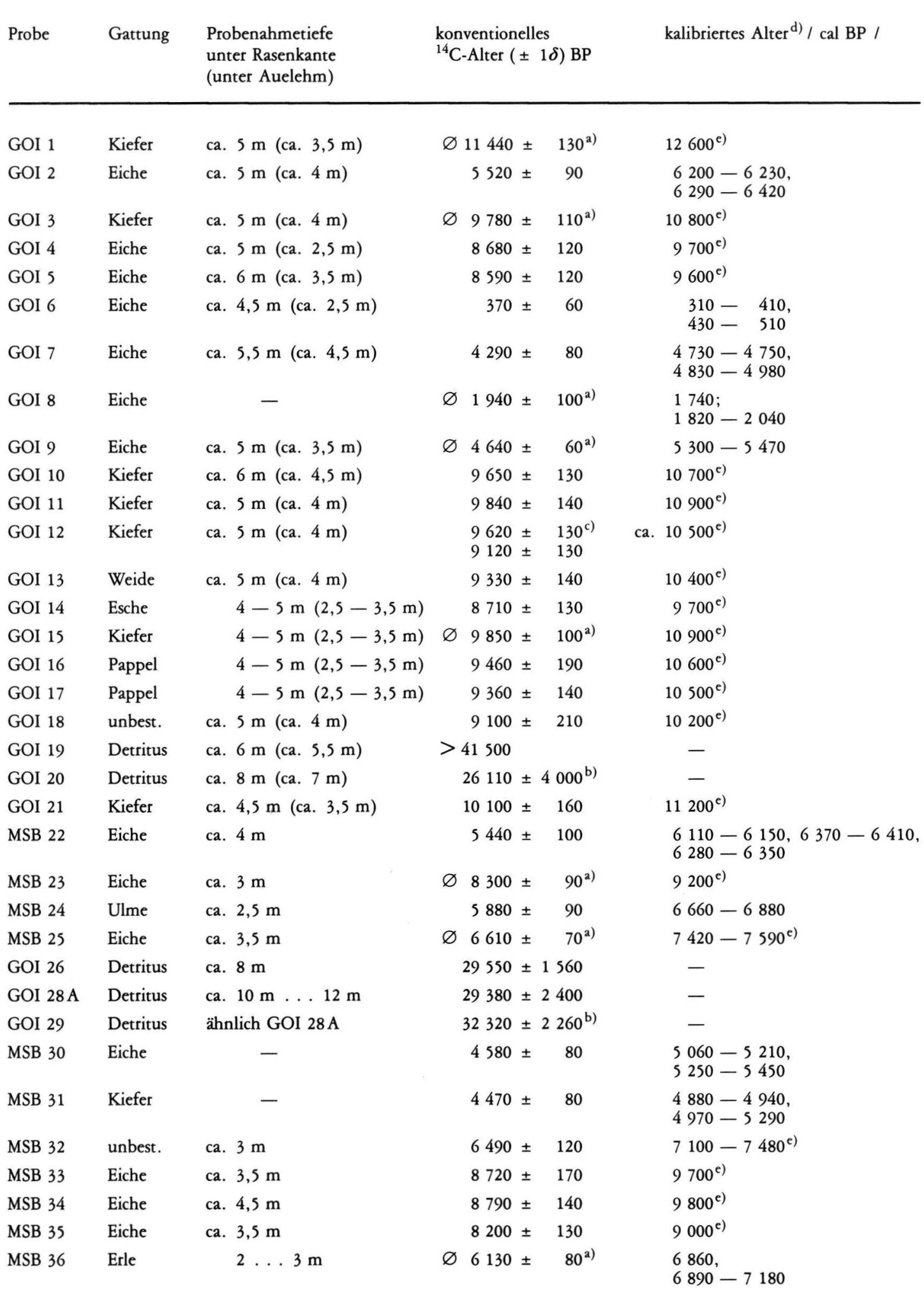


Fortsetzung Tabelle 1: ${ }^{14} \mathrm{C}$-Datierungsergebnisse subfossiler Hölzer (und organischer Substanz)

$\begin{array}{llll}\text { Probe Gattung } & \begin{array}{l}\text { Probenahmetiefe } \\ \text { unter Rasenkante } \\ \text { (unter Auelehm) }\end{array} & \begin{array}{l}\text { konventionelles } \\ { }^{14} \text { C-Alter }( \pm 1 \delta) \text { BP }\end{array} & \text { kalibriertes Alter }{ }^{\mathrm{d})} / \text { cal BP / } \\ & & \end{array}$

\begin{tabular}{|c|c|c|c|c|c|}
\hline MSB 37 & Eiche & ca. $1,7 \mathrm{~m}$ & $7600 \pm$ & 120 & $8180-8500$ \\
\hline MSB 38 & Esche & ca. $3 \mathrm{~m}$ & $4880 \pm$ & 100 & $\begin{array}{l}5480-5530 \\
5560-5740\end{array}$ \\
\hline MSB 39 & Eiche & ca. $2,5 \mathrm{~m}$ & $5210 \pm$ & 160 & $\begin{array}{l}5705-6250, \\
5760-5830, \\
5860-6250\end{array}$ \\
\hline MSB 40 & Eiche & ca. $3,5 \mathrm{~m}$ & $2650 \pm$ & 70 & $2740-2850$ \\
\hline MSB 41 & Eiche & ca. $3,2 \mathrm{~m}$ & $2900 \pm$ & 80 & $\begin{array}{l}2890-2900,3180-3210, \\
2920-3170,3235\end{array}$ \\
\hline MSB 42 & Eiche & ca. $3,5 \mathrm{~m}$ & $2930 \pm$ & 70 & $\begin{array}{l}2960-3210 \\
3230-3240\end{array}$ \\
\hline MSB 43 & Eiche & ca. $3 \mathrm{~m}$ & $2910 \pm$ & 80 & $2940-3220$ \\
\hline MSB 44 & Eiche & ca. $4 \mathrm{~m}$ & $2850 \pm$ & 70 & $2850-3150$ \\
\hline MSB 45 & unbest. & ca. $4,5 \mathrm{~m}$ & $10950 \pm$ & $190^{\mathrm{b})}$ & - \\
\hline MSB 46 & Eiche & ca. $3,5 \mathrm{~m}$ & $4670 \pm$ & 90 & $\begin{array}{l}5300-5490 \\
5520-5570\end{array}$ \\
\hline MSB 47 & Detritus & ca. $3 \mathrm{~m}$ & $6960 \pm$ & $130^{\mathrm{b})}$ & - \\
\hline MSB 48 & Detritus & ca. $4 \mathrm{~m}$ & $10370 \pm$ & $190^{\mathrm{b})}$ & - \\
\hline GRÖ 49 & Kiefer & ca. $3 \mathrm{~m}$ & $31300 \pm$ & 2000 & - \\
\hline MSB 50 & Eiche & - & $6270 \pm$ & 100 & $\begin{array}{l}7000-7300^{\mathrm{e})} \\
7030-\text { ca. } 7350\end{array}$ \\
\hline MSB 51 & Eiche & - & $6700 \pm$ & 110 & $\begin{array}{l}7400-7600^{e)} \\
7430-7650\end{array}$ \\
\hline MSB 52 & Eiche & - & $2840 \pm$ & $70^{f)}$ & $\begin{array}{l}2900-3100 \\
2860-3150\end{array}$ \\
\hline GOI 53 & Kiefer & ca. $8 \mathrm{~m}$ & $26230 \pm$ & 1400 & - \\
\hline MSB 54 & Eiche & - & $7210 \pm$ & 120 & $7920-8130^{\mathrm{e})}$ \\
\hline MSB 55 & Eiche & - & $4390 \pm$ & 90 & $\begin{array}{l}4870-5080, \\
5110-5130 \\
5190-5260\end{array}$ \\
\hline MSB 56 & Eiche & - & $3070 \pm$ & $80^{g)}$ & $\begin{array}{l}3120, \\
3100-3190,3210-3470\end{array}$ \\
\hline
\end{tabular}

a) Altersangaben sind gewichtete Mittelwerte von Doppelanalysen.

b) nur HC1-Vorbehandlung wegen zu geringer Substanzmenge.

c) Kontrolldatierung Bln $2995: 9350 \pm 60 \mathrm{BP}$.

d) Die Angabe der dendrochronologisch kalibrierten Altersbereiche erfolgt unter Berücksichtigung der Datierungsunsicherheit $( \pm 1 \delta)$ nach den Hochpräzisionskurven bzw. -tabellen von STUIVER \& PEARSON u. a. für Proben bis 6200 BP nach "weniger präzisen" und international noch nicht verbindlichen Kalibrierungsdaten von LINICK u. a., KROMER u. a., StUIVER u. a. für Proben mit $T_{r}>6200$ BP (RADIOCARBON 20 (2 B) 1986, Calibration Issue). Eine Kalibrierung der ${ }^{14} \mathrm{C}$-Daten wurde nur für fossile Hölzer vorgenommen.

e) ungefähre kalibrierte Alterswerte für $T_{r}>6200 \mathrm{BP}$ (siehe unter d) mit einer Unsicherheit von max. \pm 200 Jahren.

f) Die gesamte Baumscheibe wurde durch B. BECKER (Botanisches Institut, Universität Hohenheim/Stuttgart) dendrologisch an die süddeutschen Eichenchronologie angepaßt, wonach das Holz die Jahresringe $3064-2886 \mathrm{cal}$ BP umfaßt. Die hier datierte Probe beinhaltet etwa 20 äußere Jahrestinge (= etwa $2900 \mathrm{cal} \mathrm{BP}$ ) und ergibt in guter Übereinstimmung ein kalibriertes Alter von $2950 \mathrm{cal} \mathrm{BP}$.

g) Vgl. auch f); nach BECKER: $3279 \mathrm{cal} \mathrm{BP.}$ 
Zwei der Schluff-Muddehorizonte mit Torfeinlagerungen bei Bitterfeld haben eine überregionale $\mathrm{Be}$ deutung erlangt. Ein in den siebziger Jahren von W. MORGENEYER im Tagebau Goitsche entdeckter 2 bis $10 \mathrm{dm}$ mächtiger Horizont 2 bis $4 \mathrm{~m}$ über Schotterbasis erwies sich in der Folgezeit als ein viele Kilometer weit durchhaltender Sedimentkörper, als ein Leithorizont.

Etwa 1 bis $3 \mathrm{~m}$ höher ist ein weiteres Stillwassersediment entwickelt, das ebenfalls in torfige Ablagerungen übergehen kann, aber stärker absetzt. Diese beiden "Löbnitzer Horizonte” sind sowohl in der intakten, die heutige Aue um 2 bis $4 \mathrm{~m}$ überragenden Niederterrasse (Tagebau Rösa-Sausedlitz) als auch im gekappten Bereich unter der Aue nachgewiesen. Damit ist zum einen der Beweis der räumlichen wie stratigraphischen Zusammengehörigkeit der Schotter innerhalb und außerhalb der Aue erbracht (Abb. 3). Fünf grundsätzlich übereinstimmende ${ }^{14} \mathrm{C}$-Datierungen an Torfeinlagerungen beweisen zum anderen nunmehr definitiv auch das weichseleiszeitliche Alter der Schotter (s. auch Tab. 1).

Oberer Löbnitzer Horizont: $26230 \pm 1400$ $26110 \pm 4000$

Unterer Löbnitzer Horizont: $29380 \pm 2400$

$29550 \pm 1560$ $32320 \pm 2260$ a BP.

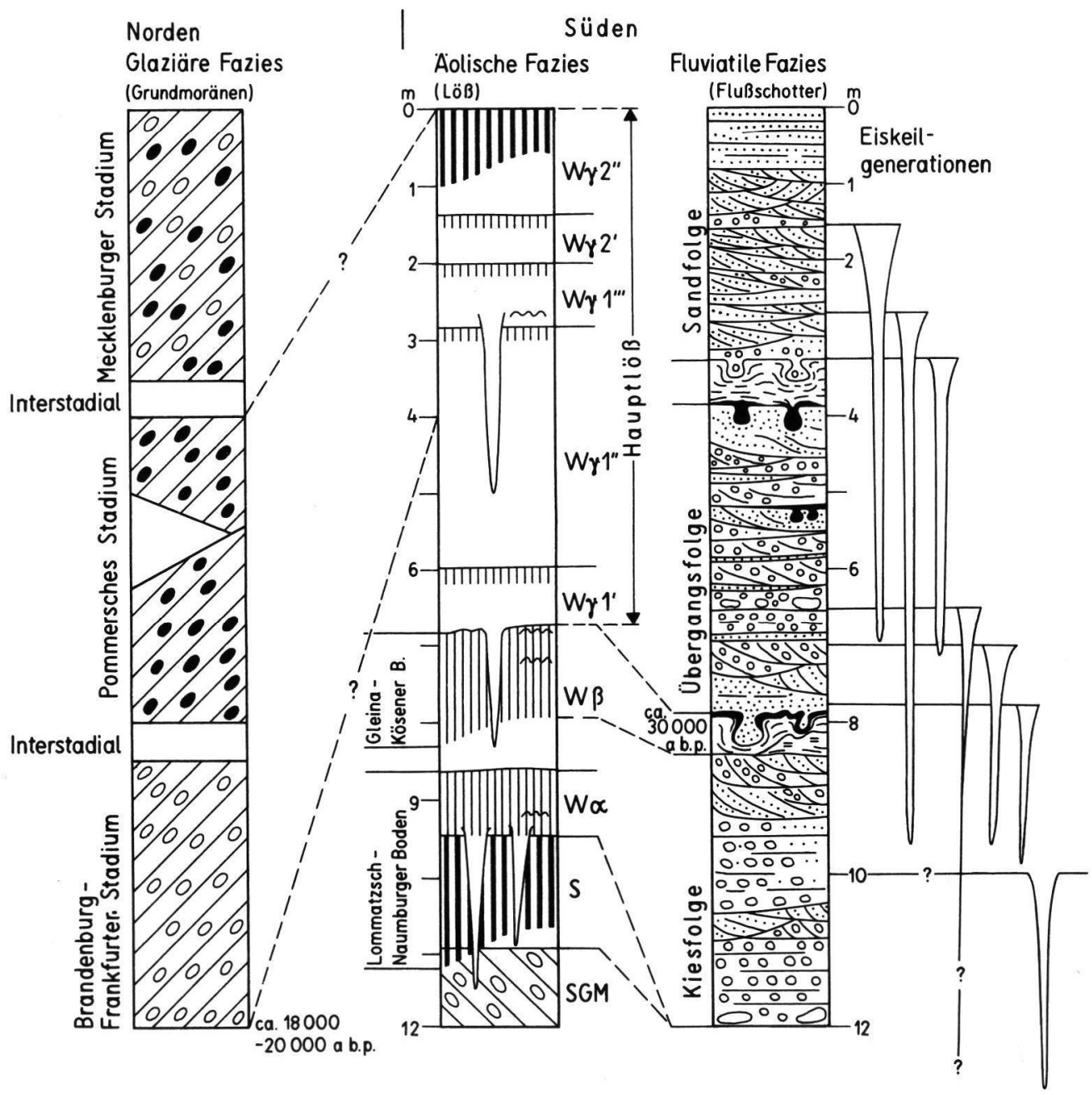

Abb. 4: Versuch einer Parallelisierung der Hauptfaziesbereiche der Weichseleiszeit im Norddeutschen Tiefland und angrenzendem Hügelland

(als äolisches Faziesprofil wurde die Lößfolge des Sächsischen Hügellandes nach LIEBEROTH 1963 gewählt). 
Die Alterswerte entsprechen dem Stillfried-B-Interstadial, für das FINK (1969) vom locus typicus ein ${ }^{14} \mathrm{C}$-Alter von $28120 \pm 200 \mathrm{bzw} .27990 \pm 300 \mathrm{a}$ angibt.

Vergleichbar sind sie damit auch dem Interstadial von Denekamp und Arcy. Da Gleinaer Bodenkomplex und Kösener Verlehmungszone innerhalb der jüngeren sächsisch-thüringischen Lößfolge wahrscheinlich dem Stillfried-B-Interstadial entsprechen (letzte Beweise fehlen noch), dürften die Löbnitzer Leithorizonte mit diesen Böden altersgleich sein. Das entspricht unserer älteren Vorstellung, wonach der weichseleiszeitliche Hauptlöß in der Übergangs-, vor allem der Sandfolge der Niederterrasse sein zeitliches Äquivalent haben soll (Abb. 4). Eine Korrelierung mit dem Vereisungsgeschehen im nördlichen Vorland des Untersuchungsgebietes ist noch weitgehend hypothetisch. Wir vermuten, daß die Sandfolge und wohl noch ein Teil der Übergangsfolge der Niederterrasse dem Brandenburger Stadium mit der maximalen Eisentfaltung um $20000 \mathrm{v}$. h. und dem Pommerschen Stadium entspricht. Während des Mecklenburger Stadiums bzw. Weichselspätglazials im weiteren Sinne erfolgte bereits wieder fluviatile Erosion und damit die Zerstörung der Niederterrasse.

Im nördlichen Untersuchungsgebiet (Bad Düben, Bitterfeld) liegt auf der Niederterrasse über einer losen Steinsohle ein einige Dezimeter mächtiger Sandlöß und / oder Treibsand. Im Lößgürtel sind Stel- len bekannt, bespielsweise nördlich von Pegau, wo die Basis des Weichsellößkomplexes einige Meter tiefer als die Oberfläche der Niederterrasse liegt (FuHRMANN 1976, Abb. 10, hier schematisch Abb. 1).

Das hat FuHRmanN dazu bewogen, die liegenden Niederterrassenschotter mit Vorbehalt in die sog. Fläming-Kaltzeit einzustufen und die weichseleiszeitliche Niederterrasse auf einen schmalen Streifen unmittelbar unter der Aue einzuengen.

Wir teilen diese Ansicht vor allem auch aus der Sicht der Gesamtzusammenhänge des sächsischen Tieflandes nicht und meinen, daß Lößaufwehung und fluviatile Akkumulation in der Endphase der Niederterrassenzeit nebeneinander abliefen, zumal die erosive Kraft des Flusses in dieser Akkumulationsphase weitgehend gebändigt war.

\section{Spät- und nacheiszeitliche Flußtalentwicklung}

Mit dem Eiszerfall der Weichselvergletscherung wurden die Niederterrassen durch Erosion stark zerschnitten bzw. auch ausgeräumt. Dieser Prozeß muß während des Spätglazials (Alleröd - Jüngere Dryas) bereits abgeschlossen gewesen sein, denn an der Erosionsbasis wurden sowohl radiometrisch als auch pollenanalytisch organogene Sedimente entsprechender Zeitstellung nachgewiesen (Abb. 5 und 6). Aus anderen Flußgebieten Mitteleuropas ist eine Phasen-

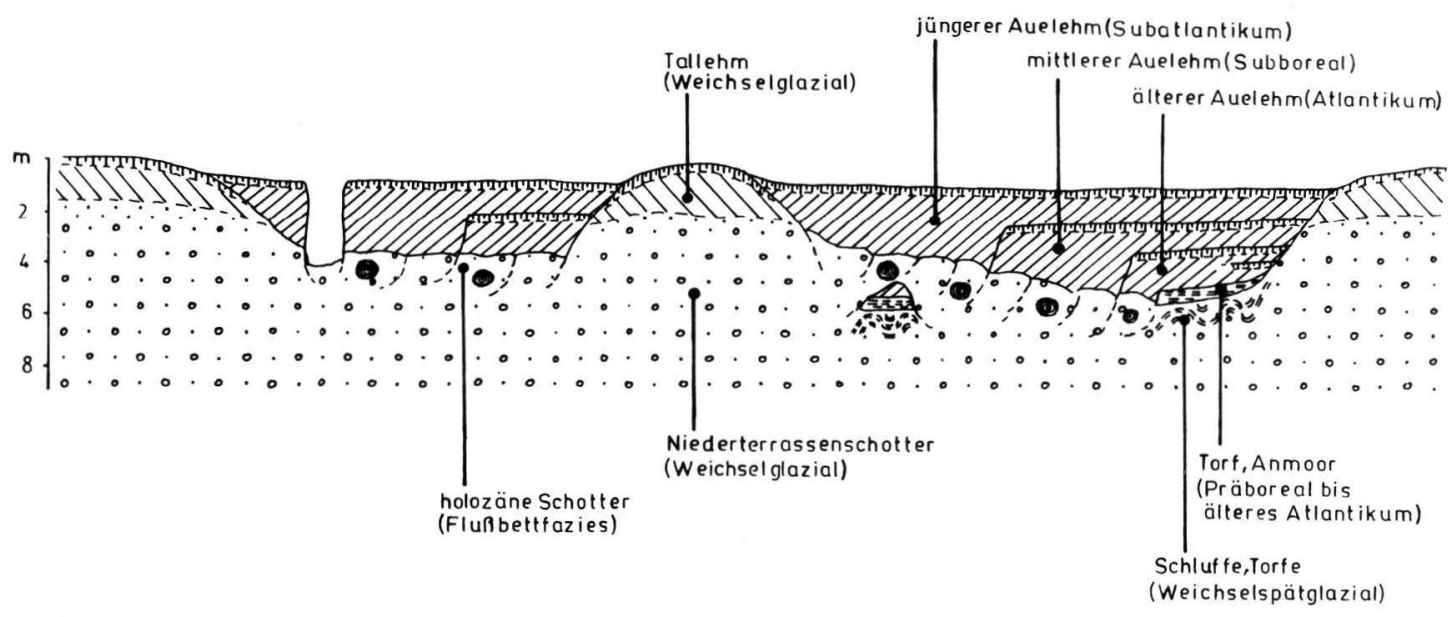

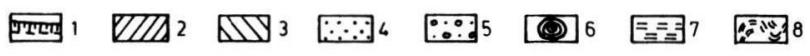

Abb. 5: Schnitt durch die jungquartäre Schichtenfolge im Tal der Weißen Elster (Unterlauf) aufgrund von Tagebauaufnahmen.

1 - Bodenhorizont; 2 - Schluff, sandig, tonig, humos, braun (Auelehm);

3 - sandiger Schluff, hellbraun (Tallehm); 4-Sand; 5-Kies; 6- subfossile Hölzer ;

7 - Niedermoor bzw. Anmoor; 8 - kryoturbat deformierte Schluffe mit Torflagen. 
haftigkeit dieser Erosion durch z. T. mehrere Terrassenniveaus belegt (z. B. Main, vgl. SCHIRMER 1983). Für die Flußgebiete von Mulde und Weißer Elster wird dies durch die sog. Tallehmterrasse angedeutet (Abb. 3 und 5 ).

Die spätglaziale und holozäne Flußdynamik spielte sich zunächst in breiten, 5 bis $10 \mathrm{~m}$ tief in die Niederterrasse eingeschnittenen Rinnen ab. Zur Erfassung der Sedimentationsprozesse ließen sich Stratotypen in Abhängigkeit vom Faziesbereich herausarbeiten (Abb. 6). Eine gesicherte chronostratigraphische Bestimmung der Sedimentkörper bildete die Voraussetzung, um z. T. gleichzeitig ablaufende Sedimentationsvorgänge in unterschiedlichen Bereichen innerhalb der Aue erfassen zu können. Es ist also notwendig zu unterscheiden zwischen dem Bereich der Aue, der durch fluviatile Prozesse im Flußbett beeinflußt wurde (Flußbettfazies) und dem Bereich der Aue, der außerhalb des Flußbettes blieb.

Naturgemäß werden im Flußbett ständig Kiese und Sande um- bzw. abgelagert. Hierbei kommt es auch zur Einbettung von Hölzern. Nach deren Radiokarbondatierung sowie der Dendrochronologie kann die Auffassung HäNDELs (1967, 1982) nicht aufrecht erhalten werden, daß im Flußgebiet der Weißen Elster lediglich zwei holozäne Schotterkörper, ein älterer aus dem Atlantikum und ein jüngerer aus dem Mittelalter bis zur Neuzeit, unterschieden werden können. Aus der gesamten Zeitdauer des Holozäns lassen sich Kiese und Sande der Flußbettfazies nachweisen, die durch subfossile Hölzer eine nähere Datierung erfahren (Abb. 7). Lediglich die Belegungsdichte weist im Laufe der Zeit gewisse Unterschiede auf, die teilweise statistisch bedingt sind (Problem der Repräsentanz in Abhängigkeit der Stichprobenanzahl), teilweise aber auch Phasen verstärkter seitlicher Flußbettverlagerungen erkennen lassen. Profiluntersuchungen in Tagebauaufschlüssen innerhalb der Auen im Arbeitsgebiet verdeutlichen, daß sich die holozänen Schotter nicht als einheitlicher, vertikal aufgebauter Sedimentkörper charakterisieren lassen, wie dies im vorangehenden Abschnitt für die weichselzeitlichen Niederterrassenschotter beschrieben wurde. Die holozänen Schotter werden durch Lateralerosion horizontal um- bzw. abgelagert, wobei als Ausgangsmaterial weichselglaziale Niederterrassenschotter zur Verfügung stehen. Lithologisch läßt sich deshalb zwischen beiden auch kein Unterschied feststellen. Die Sedimente der nacheiszeitlichen Flußbettfazies sind in die Niederterrasse eingeschachtelt. Durch häufige Flußbettverlagerungen kam es immer wieder zu Aufarbeitungen älterer holozäner Schotter mit subfossilen Hölzern. Dadurch wird auch verständlich, daß unmittelbar benachbart eingebettete Stämme und Fragmente von Auenwaldgehölzen sehr unterschiedlich Radiokarbonaten erbracht haben (vgl. Abb. 6).
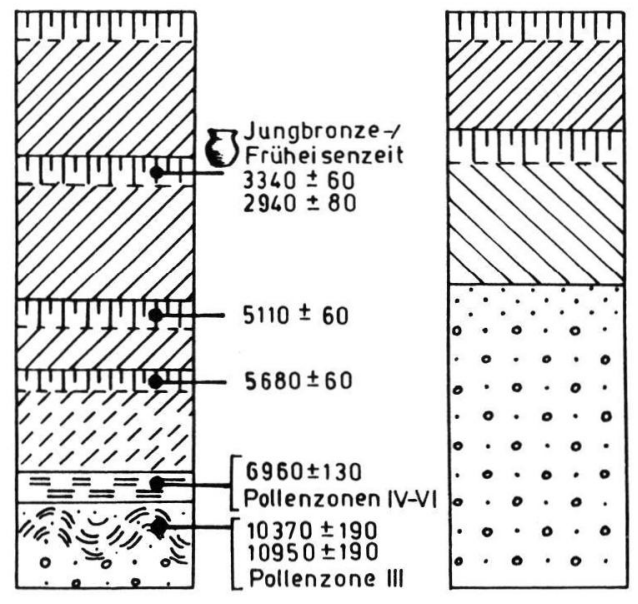

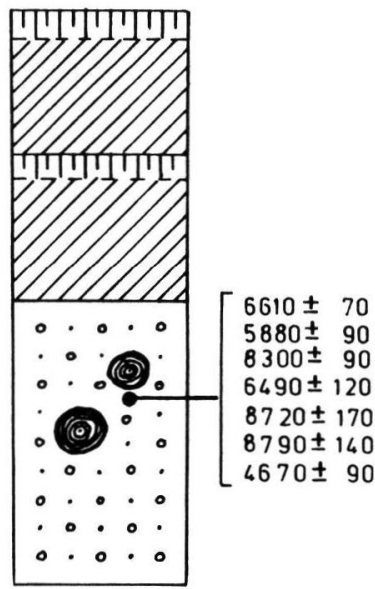

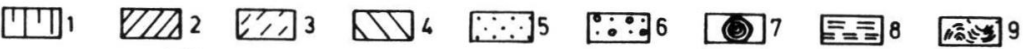

Abb. 6: Stratotypen in Abhängigkeit vom Faziesbereich

(Auswahl aus der Elster-Luppe-Aue, Tagebau Merseburg-Ost).

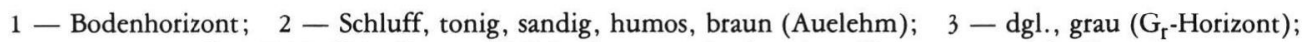
4 - sandiger Schluff, hellbraun (Tallehm); 5-Sand; 6-Kies; 7 - subfossile Hölzer;

8 - Niedermoor bzw. Anmoor; $9-$ Schluffe, Sande mit organogenen Einlagerungen, kryoturbat deformiert. 


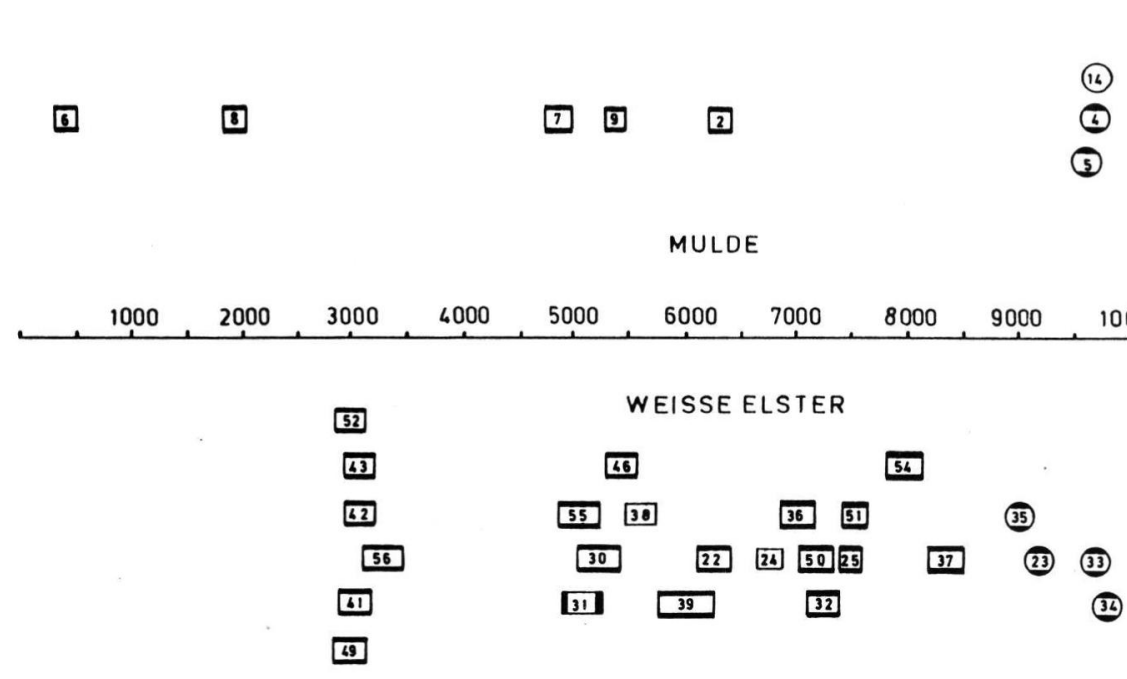

Abb. 7: Kalibrierte Radiokarbonaten von subfossilen Hölzern (vgl. Tab. 1),

(16) (13) (11)

(1) (12)(3) (2)

\section{(15) (15)

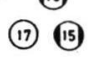


kungen bzw. Niederschlagsveränderungen der Nacheiszeit sicherlich als modifizierende, jedoch wohl kaum als hauptsächliche Faktoren bei der Auelehmbildung anzusehen sind. Auenstratigraphische Befunde könnten Klimaschwankungen auch vortäuschen, denn verstärkte seitliche Flußbettverlagerungen und flächenhafte Akkumulation sind zunächst nur Ausdruck von Veränderungen des Wasserhaushaltes und der Sedimentzufuhr. So wie derartige Prozesse durch mittelbare klimatisch bedingte Vegetationszerstörung verursacht worden sein können (was jedoch für das Holozän in Mitteleuropa auszuschließen ist), wirkten sich flächenhafte Rodungen im selben Sinne aus.

Aus den regionalen Befunden nordwestsächsischer Flußtäler darf abgeleitet werden, daß die Flußdynamik als komplexes Wirkungsgefüge (abhängig von Wasserhaushalt, Gestein, Relief, Boden, Vegetation, Klima usw.) im Holozän durch anthropogene Einflüsse vielfach überprägt wurde. Es ist offensichtlich, daß der unterschiedliche Beginn und Verlauf der Auelehmbildung in einander nahe benachbarten Flußgebieten mit Besiedlungsvorgängen in den entsprechenden Räumen korrespondiert (LITT 1988). In den Tälern von Pleiße und Weißer Elster setzte die Auelehmsedimentation ein, als dieser Raum durch die ersten Ackerbauern und Viehzüchter (sog. Bandkeramiker) extensiv genutzt wurde. Im Gegensatz hierzu wurde das benachbarte Muldegebiet während des Atlantikums von neolithischen Bauern weitgehend gemieden. Auelehme entsprechender Zeitstellung sind aus diesem Raum bislang auch unbekannt. Bronzezeitliche Funde aus den älteren feinklastischen Hochwassersedimenten in der Muldeaue östlich von Bitterfeld bieten einen terminus ad quem bzw. terminus post quem für die Auelehmbildung dieses Einzugsgebietes. Dies stimmt gut mit den siedlungsarchäologischen Befunden (SCHMIDT 1981) überein, denn erst der jungbronzezeitliche Landesausbau läßt im Gebiet der Vereinigten Mulde spürbare Veränderungen des Ablußregimes und des Sedimentationsverhaltens erwarten.

Die insbesondere für das Flußgebiet der Weißen Elster vom Zentralinstitut für Isotopenforschung Leipzig ermittelten radiometrischen Daten erlauben die Rekonstruktion der nacheiszeitlichen Flußgeschichte, die überdies durch ${ }^{14} \mathrm{C}$-Datierungen an begrabenen Böden, durch pollenanalytische und archäologische Befunde (LITT u. a. 1987) sowie durch erste Ergebnisse dendrochronologischer Untersuchungen an subfossilen Eichen (BECKER et al. 1989) flankiert werden. Aus diesen Daten lassen sich folgende Modellvorstellungen über die holozäne Flußtalentwicklung der unteren Laufabschnitte von Pleiße und Weißer Elster ableiten (vgl. Ablaufschema Abb. 8):
Im Frühholozän war der morphologische Unterschied zwischen Tallehmterrasse und Aue markant ausgeprägt, denn der Talboden lag 2 bis $4 \mathrm{~m}$ tiefer als heute. Das Abflußregime verlief bis in das ältere Atlantikum hinein recht ausgeglichen, da offenbar die geschlossene Waldvegetation im Einzugsgebiet mögliche hygrische Schwankungen pufferte. In jener Zeit kam es zu keiner wesentlichen Talbodenerhöhung, denn Akkumulation und Erosion befanden sich im angenäherten Gleichgewicht (mit der Tendenz zur weiteren Eintiefung). Im Flußbettbereich dominierten Umlagerungsprozesse, und außerhalb des Flußbettes kam es zur Torfbildung oder Pedogenese. Mit dem Einsetzen der Auelehmbildung, als Resultat von Rodung und Ackerbau der Bandkeramiker, erhöhte sich der Talboden während des jüngeren Atlantikums und blieb später oberhalb des permanenten Grundwasserniveaus (vgl. Grenze zwischen $G_{0}$ - und $G_{r^{-}}$Horizont, Abb. 6). Dies hatte natürlich Konsequenzen für die Vegetationszusammensetzung in der Aue (geringer Anteil von Ried und Bruchwald). Die Auelehmbildung während des Atlantikums, die bemerkenswerterweise auf das Altsiedelgebiet beschränkt blieb, wurde durch ein bis zwei Bodenbildungen unterbrochen.

Die durch Radiometrie (Abb. 7) und Dendrochronologie (BECKER et al. 1989) gewonnenen Daten von subfossilen Hölzern lassen für das Subboreal, insbesondere für den Zeitraum 1350 bis 900 v. u. Z., intensivere seitliche Flußbettverlagerungen vermuten. Außerhalb des Flußbettes kam es während des Subboreals überdies zur verstärkten Auelehmsedimentation, wobei ältere Ablagerungen sowie auch ehemalige Flußbettbereiche überdeckt wurden. Aufgrund siedlungsarchäologischer Befunde darf abgeleitet werden, daß die spürbaren Veränderungen des Abflußverhaltens offenbar im Zusammenhang mit der intensiven bronzezeitlichen Besiedlung dieses Raumes stehen. Eine Ruhepause in der Sedimentation, wie sie von HÄNDEL (1967) für den Zeitraum zwischen Atlantikum und Subatlantikum angenommen wurde, kann nicht bestätigt werden ${ }^{2}$ ). Erst am Ende des

2) Als Schlüsselbefund für eine Sedimentationsruhe zwischen Atlantikum und Subatlantikum führte HÄNDEL Profilbefunde aus Löbschütz, Kr. Leipzig, an, wonach von einem gegenwärtig begrabenen Boden ausgehend, Gruben im Zeitraum von der Stichbandkeramik bis zur Latenezeit eingetieft wurden. Somit kann die Überdeckung erst nach der Latenezeit erfolgt sein. Eine erneute Überprüfung der Geländesituation ergab jedoch, daß es sich im gegebenen Falle nicht um einen begrabenen Boden auf Auelehm, sondern auf weichselzeitlichem Tallehm handelt. Das Profil befindet sich $z$. T. in Hangposition, und die ehemalige Geländeoberfläche der Tallehmterrasse (die bereits im geologischen Meßtischblatt von GRAHMANN als solche kartiert wurde) ist im Subatlantikum kolluvial überdeckt worden. 


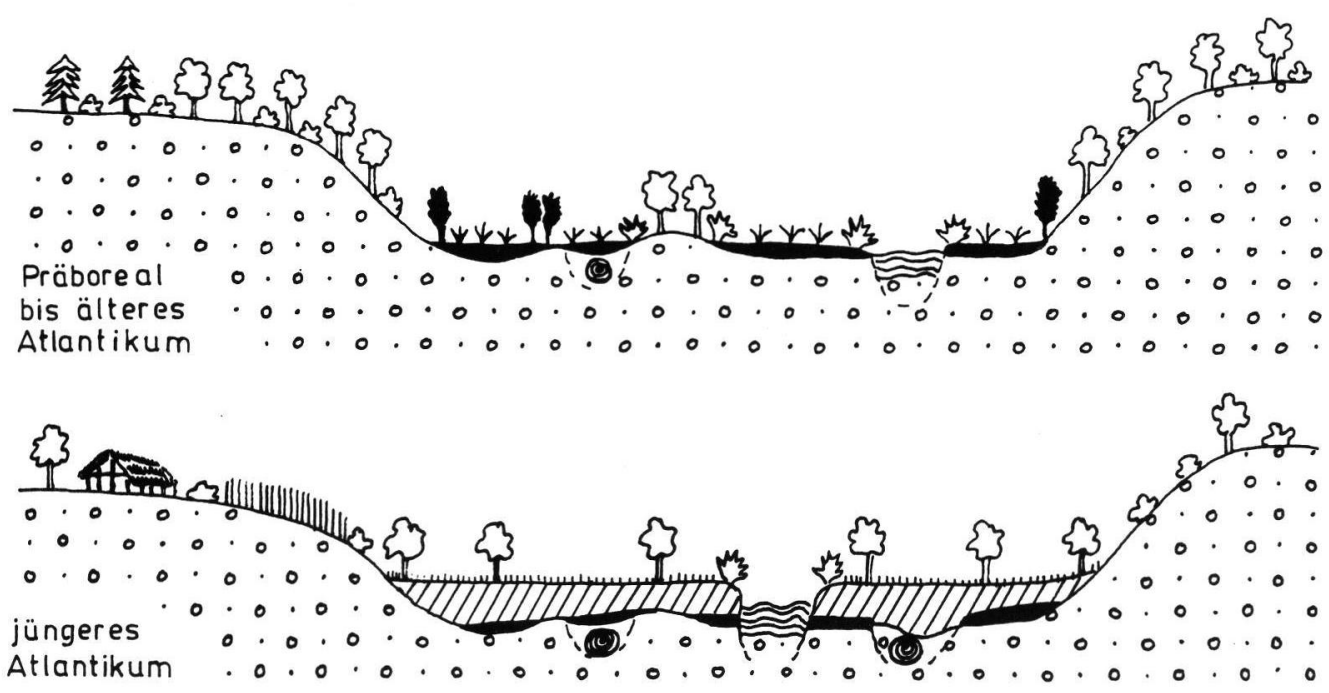

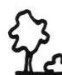
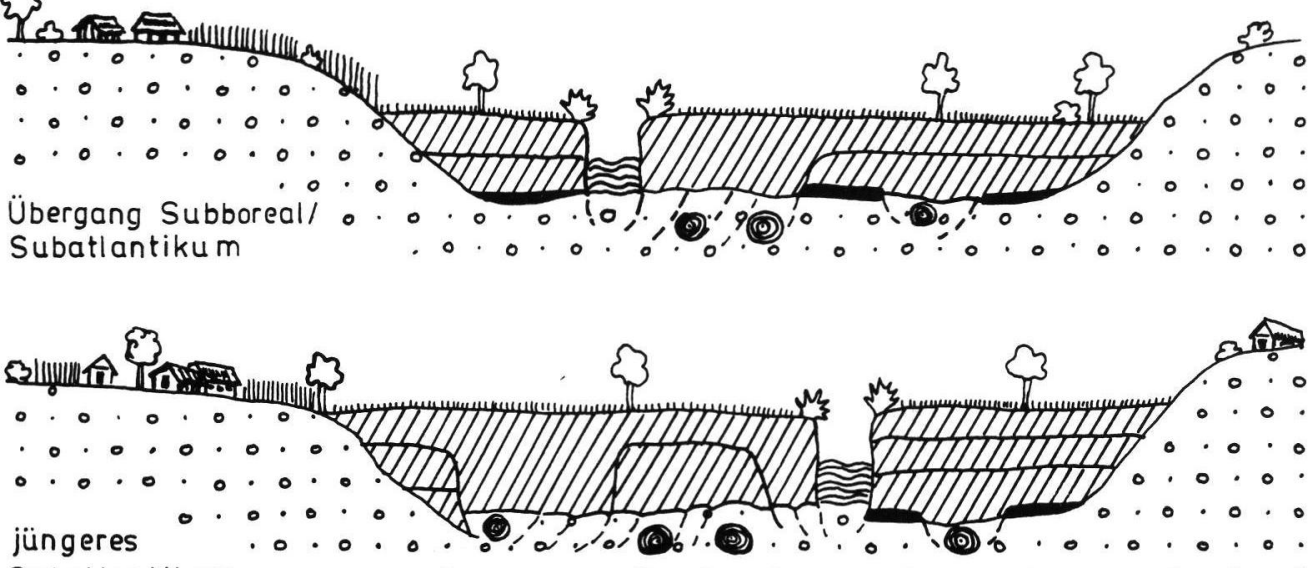

Subatlantikum $0.0 .0 .0 .0 .0 .0 .0 .0 \cdot 0.0 .0 .0 .0 .0 .0 .0$

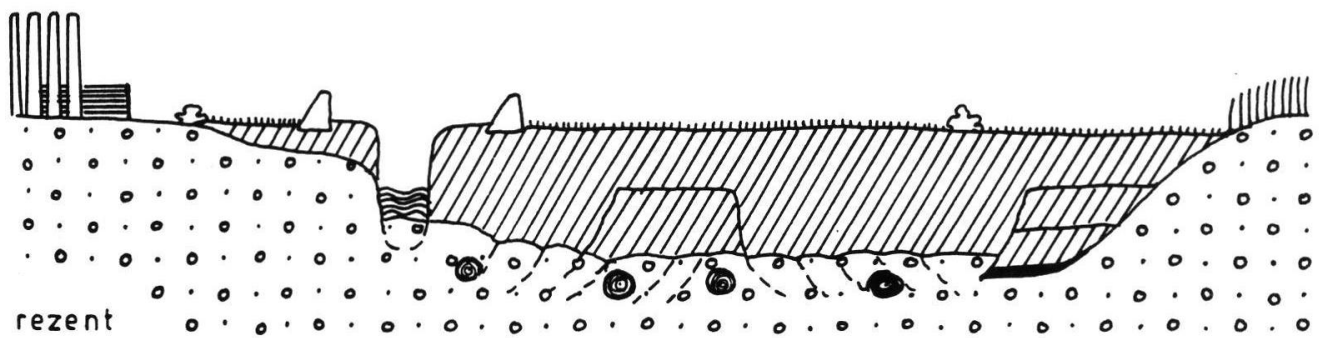

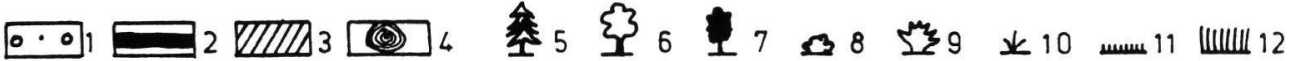

Abb. 8: Ablaufschema der holozänen Talentwicklung im Unterlauf der Weißen Elster.

Die holozäne Aue ist in die Niederterrasse eingeschachtelt. In der Darstellung wurde die Korngrößenabnahme innerhalb der Niederterrasse vom liegenden Schotter zum hangenden Tallehm nicht dargestellt.

1 - Kiese und Sande; 2 - Niedermoor bzw. Anmoor; 3 - Auelehm;

4 - subfossile Hölzer; 5-Kiefern; 6-Eichen und andere Laubbäume; 7 - Erlen; 8 - Sträucher; 9 -Weiden; $10-$ Naßwiese; 11 - Frischwiese; 12 - Getreidefeld. 
Subboreals deuten pedogene Prozesse auf geringe Sedimentationsraten.

Im Subatlantikum verstärkten sich die anthropogenen Einflüsse auf die Flußtalentwicklung. Bei häufigeren Hochwässern wurden durch Lateralerosion ältere $\mathrm{Ab}$ lagerungen ausgeräumt bzw. umgelagert. Der holozäne Talboden erhöhte sich weiter mit erneut und verstärkt einsetzender Auelehmbildung. Der morphologische Unterschied zwischen Tallehmterrasse und Aue wurde zunehmend verwischt, z. T. kam es sogar zur Überdeckung tiefliegender Niederterrassenbereiche sowie zur Nivellierung der gesamten Talbreite. Offenbar war die Rodung der Auenwälder im jüngeren Subatlantikum weit fortgeschritten, denn die entsprechenden Sedimente der Flußbettfazies sind auffallend arm an subfossilen Hölzern. Gegenwärtig sind große
Laufabschnitte der nordwestsächsischen Flüsse kanalisiert und eingedeicht.

Die für den Unterlauf der Weißen Elster modellartig dargestellten Sedimentationsprozesse während des Holozäns lassen sich naturgemäß nicht schematisch auf andere mitteleuropäische Flußgebiete übertragen. So wurden für das südliche Mitteleuropa von SCHIRMER (1983) holozäne Flußterrassen im Maintal beschrieben, die in unserem Raum nicht beobachtet werden können. Auch im Flußgebiet der Weser wurden von LÜTTIG (1960) und STRAUTZ (1962) verschiedene holozäne Auenstufen kartiert. Ihnen zufolge soll jeder Stufe ein eigener Akkumulationskörper mit der Sedimentfolge Kies - Sand - Auelehm angehören. Dieses Bild konnte in jüngster Zeit durch Untersuchungen von LIPPS (1988) sowie LIPPS \& CASPERS

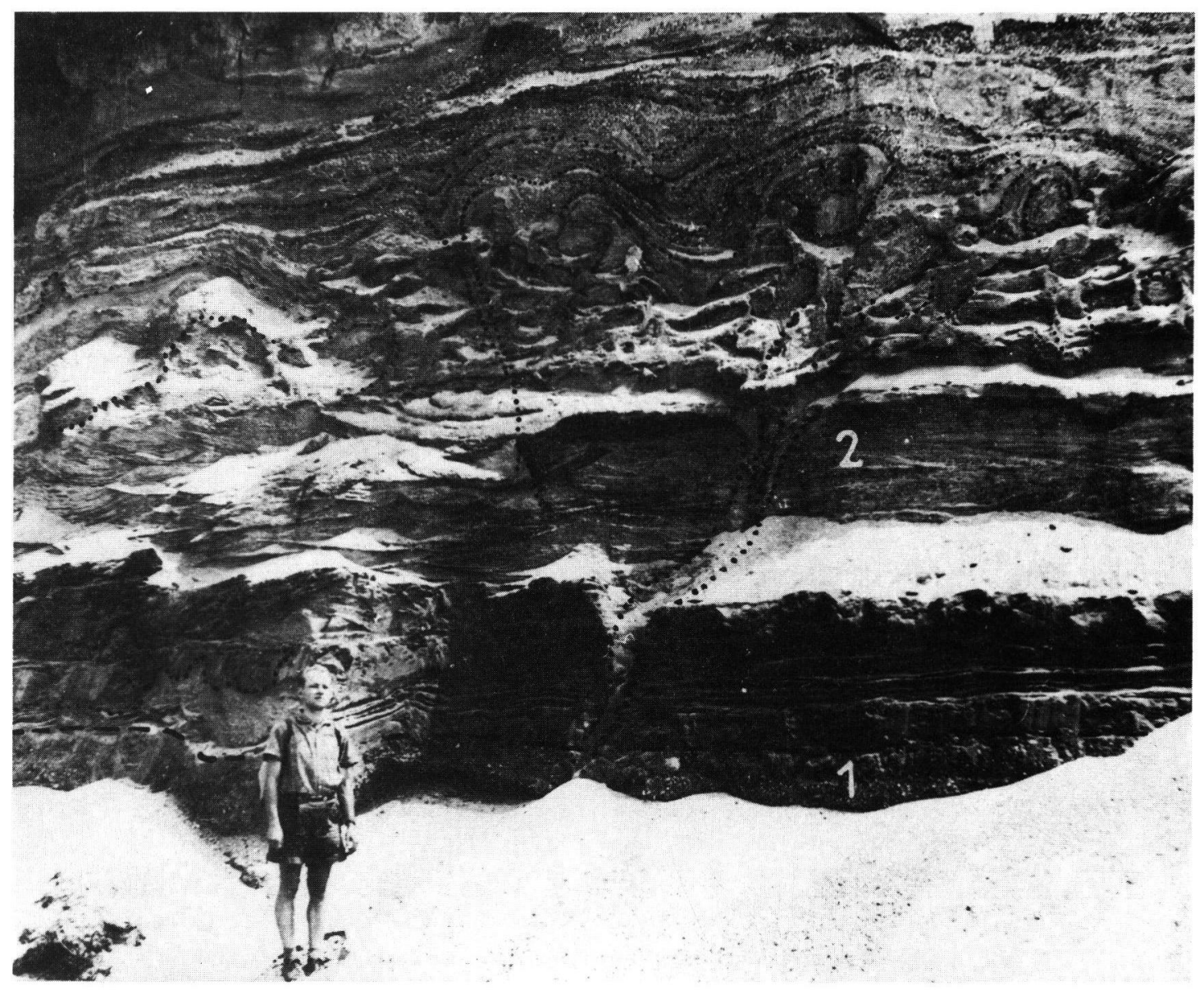

Abb. 9: Niederterrasse der Mulde im Tagebau Goitsche bei Bitterfeld.

Intensive gravitative Verbrodelung, Eiskeilpseudomorphosen. 1 - Untere grobe Folge;

2 - (Mittlere oder) Übergangsfolge mit Löbnitzer Schluff-Mudde-Horizont weniger Dezimeter über der Basis

(unterhalb der hellen Sandschürze). 
(1990) im Mittelwesertal präzisiert werden. Daraus konnte abgeleitet werden, daß die Auelehmsedimentation offenbar erst in der vorrömischen Eisenzeit bzw. in der ausgehenden Bronzezeit einsetzte und durch zunehmende Rodungen im Einzugsgebiet der Weser ausgelöst wurde. Unterschiede ergeben sich auch zum Jungmoränengebiet. Im polnischen Tiefland lassen sich am Beispiel des Warta-Tales oberflächig sichtbare Mäandergenerationen seit dem Alleröd feststellen, wobei die Altwasserarme wie Seen verlandeten und mit organogenen Sedimenten gefüllt waren (sog. oxbow lakes, KOZARSKI 1983). Im Gebiet der Leipziger Tieflandsbucht sind vergleichbare Mäandergenerationen im oberflächennahen Bereich der Aue unbekannt, denn durch die starke feinklastische Sedimentation wurden ältere Flußrinnen relativ schnell mit Auelehm überdeckt bzw. fielen der Erosion zum Opfer. Die heute noch sichtbaren Flußschlingen und Altwasserarme besitzen aufgrund pollenanalytischer Untersuchungen in der Elster-LuppeAue ein sehr junges Alter (jüngeres Subatlantikum, Neuzeit). Holzanatomische Untersuchungen von C. SCHIRAREND (Berlin) geben Hinweise auf die Gehölzzusammensetzung in den Flußtälern des Arbeitsgebietes. In der Übersichtstabelle der Radiokarbondaten wurden die Gattungen der subfossilen Hölzer vermerkt. Danach ist die Eiche am häufigsten, gefolgt von Kiefer, Pappel, Esche, Ulme, Weide und Erle. Bis auf die Kiefer fügen sich die übrigen Gattungen gut in das Spektrum der gegenwärtigen Auenwaldvegetation ein. Die aktuelle Geobotanik unterscheidet zwischen der ufernahen Weichholzaue (SaliciPopuletum) mit verschiedenen Weiden- und Pappelarten und einer uferfernen sowie auf einem höheren Niveau stockenden Hartholzaue (Fraxino-Ulmetum) mit Eiche, Esche und Ulme. Die Kiefer ist zwar in der Lage, auf Moorböden zu wachsen, jedoch verträgt sie keine länger andauernden Überflutungen und ist somit kein eigentlicher „Auenwaldbaum”. Lediglich in gebirgsnahen Flußauen (Kalkschotterböden einiger Flußtäler in den Alpen) kommt die Kiefer gegenwärtig auf trockenen und nährstoffarmen Standorten vor (vgl. zusammenfassend bei ELLENBERG 1982). Nun ist es sicherlich problematisch, die gegenwärtigen Vegetationsverhältnisse in allen Details auf die Vergangenheit zu übertragen, denn gerade die besondere Dynamik der Flußtalentwicklung hat großen Einfluß auf die Konkurrenzverhältnisse innerhalb der Phytozönosen. Die Häufigkeitsverteilung der Gattungen Quercus und Pinus in Abhängigkeit von der Zeit (Abb. 7) verdeutlicht, daß die Kiefer im Spätglazial und vor allem im Frühholozän (Präboreal) in den Flußtälern von Weißer Elster und Mulde verbreitet war. Im Zuge der endgültigen Wiederbewaldung

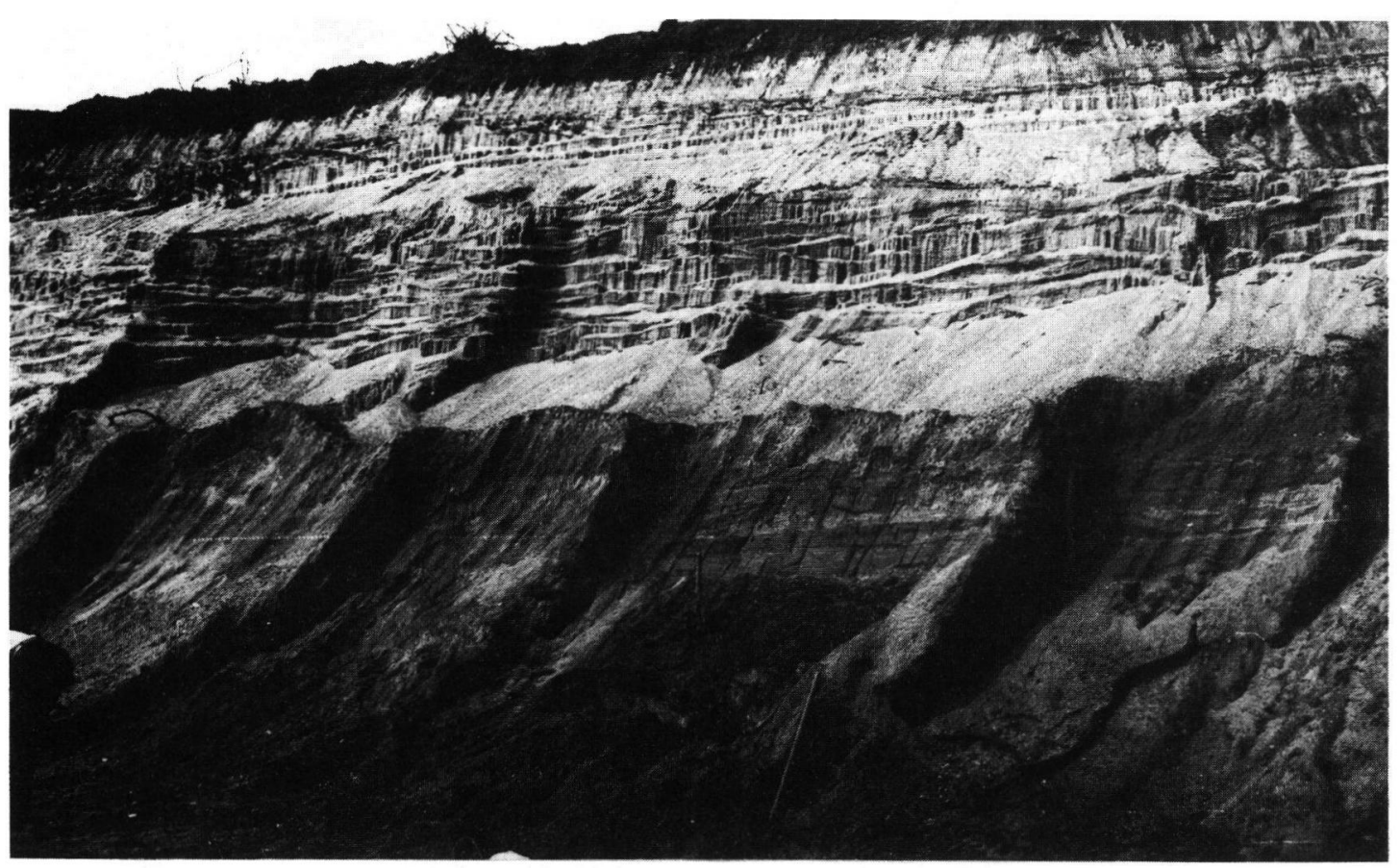

Abb. 10: Niederterrasse der Mulde wie Abb. 9 ab Unterem Löbnitzer Schluff-Mudde-Horizont mit Übergangsfolge (intensive Schrägschichtung) und Obere (Sand-) Folge. Tagebau Rösa-Sausedlitz. Foto S. WANSA 1989. 


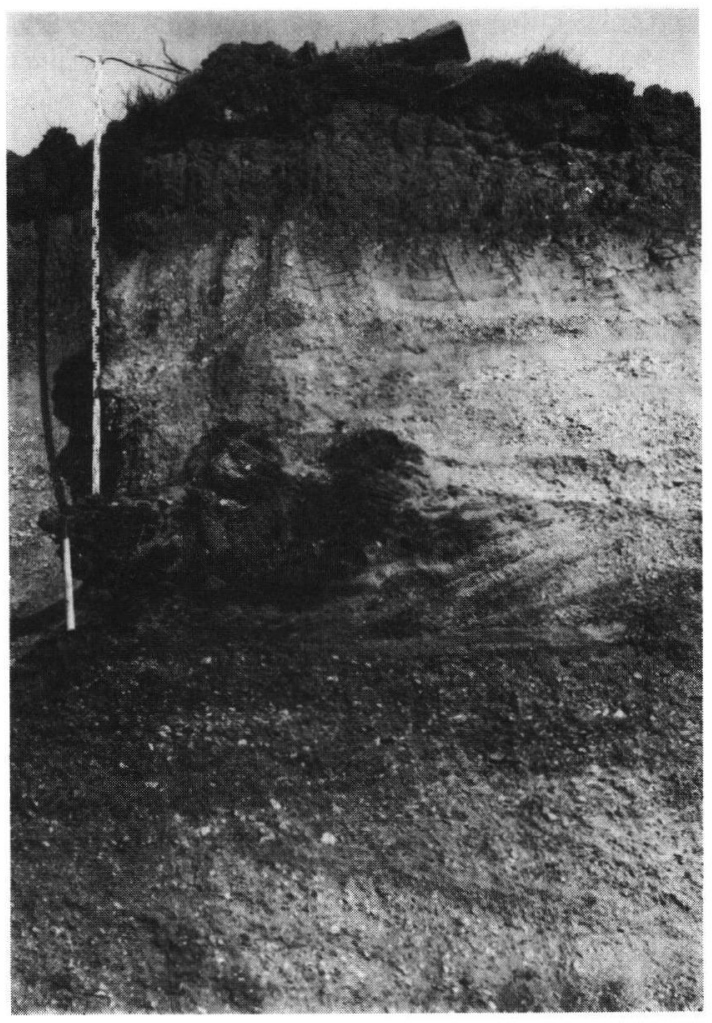

Abb. 11: (oben)

Subfossile Schottereiche, eingebettet

in Sedimente der holozänen Flußbettfazies und überdeckt durch jungen Auelehm.

Tagebau Merseburg-Ost (Elster-Luppe-Aue).
Abb. 12: (unten)

Durch begrabene Böden (Vegas)

gegliederte Auelehmdecke.

Im Liegenden ist als schwarze Lage der früh-bis mittelholozäne Torf bzw.

Anmoor erkennbar.

Tagebau Merseburg-Ost (Elster-Luppe-Aue).

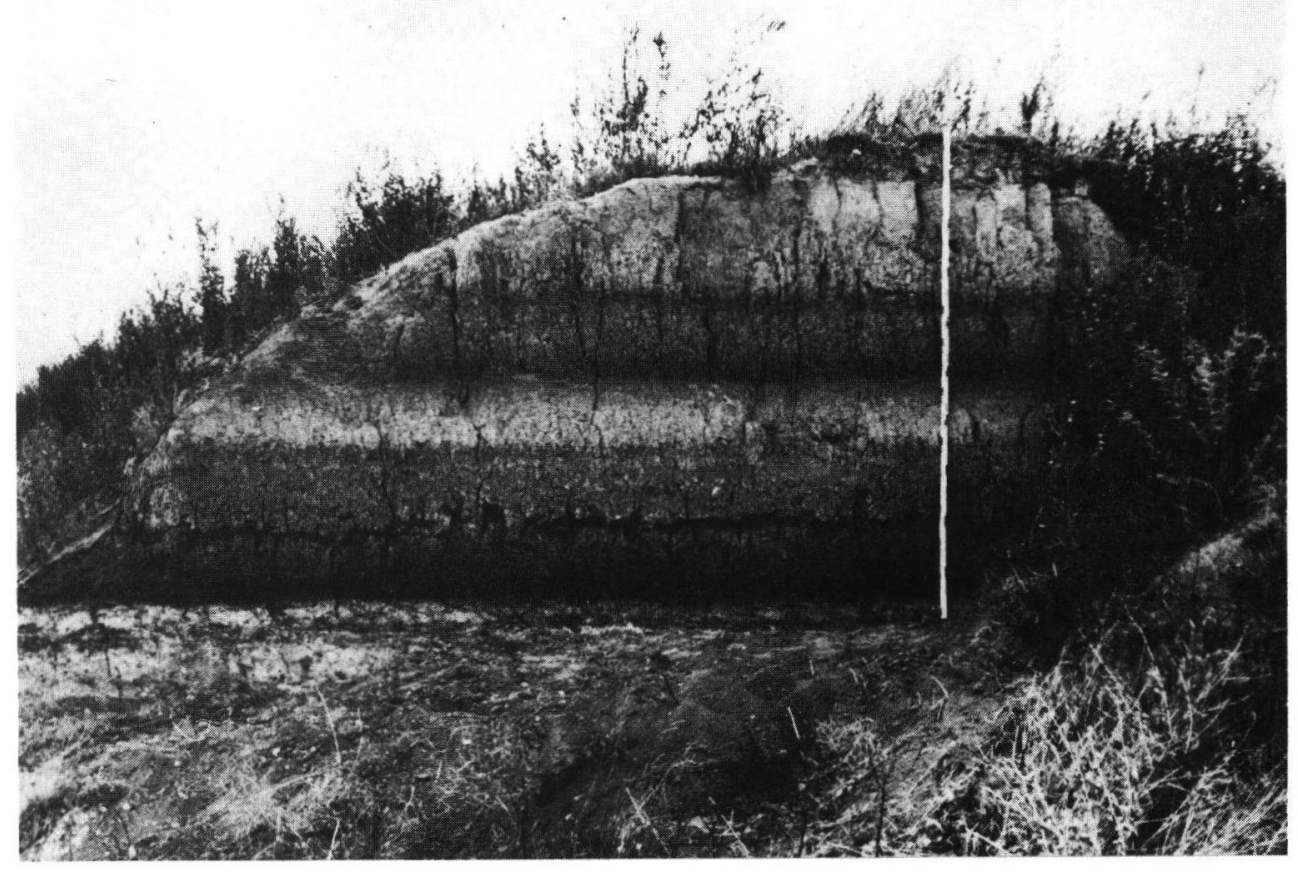


Mitteleuropas während des Präboreals durch KiefernBirken-Wälder wird Pinus in den Flußtälern nicht nur die Niederterrassen, sondern auch tiefliegende Niederterrassenreste und grundwasserferne Bereiche des Talbodens besiedelt haben, denn entsprechende Stämme wurden in jener Zeit regelmäßig durch Lateralerosion eingeschottert. Die Pappel war offensichtlich während des Frühholozäns in den Auen ebenfalls vertreten. Noch im Boreal verdrängte die Eiche in zunehmendem Maße die Kiefer aus den Flußtälern (vgl. auch BECKER 1982). Die ältesten mitteleuropäischen Flußeichen des Holozäns wurden dendrochronologisch lückenlos bis 7237 v. u. Z. erfaßt (BECKER et al. 1989). Durch diese Radiokarbondaten konnten die ersten Eichengenerationen für unser Arbeitsgebiet ebenfalls ermittelt werden (ältestes ${ }^{14} \mathrm{C}$-Datum 8790 \pm 140 BP). Die Flächen mit Hartholzvegetation (mit Quercus robur als dominierender Auenwaldart) wurden jedoch erst später durch die Auelehmsedimentation größer, denn die Erhöhung des Talbodens verringerte die Grundwasserbeeinflussung, wodurch auch die Ried- und Bruchwaldvegetation zurückgedrängt wurde.

\section{Schriftenverzeichnis}

BANNISTER, B. \& DAMON, P. E. (1972): A dendrochronologically-derived primary standard for radiocarbon dating. - Proc. of the $8^{\text {th }}$ Intern. Conf. on Radiocarbon Dating: 480-489; Wellington.

BECKER, B. (1982): Dendrochronologie und Paläoökologie subfossiler Baumstämme aus Flußablagerungen. Mittlgn. Komm. Quartärforschung österr. Akad. Wiss., 5: $120 \mathrm{~S}$.; Wien.

BECKeR, B., JäGER, K.-D., KAUfMANN, D. \& LITT, T. (1989): Dendrochronologische Datierungen von Eichenhölzern aus den frühbronzezeitlichen Hügelgräbern bei Helmdorf und Leubingen (Aunjetitzer Kultur) und an bronzezeitlichen Flußeichen bei Merseburg. - Jschr. mitteldt. Vorgeschichte, 72: 299-312; Berlin.

EIsSmanN, L. (1975): Das Quartär der Leipziger Tieflandsbucht und angrenzender Gebiete um Saale und Elbe. - Schriftenreihe geol. Wiss., 2: 236 S.; Berlin.

ELlenberG, H. (1982): Vegetation Mitteleuropas mit den Alpen. - 989 S.; Stuttgart (Ulmer).

FinK, J. (1969): Les loess en Autriche. - Bull. de l'Assoc. franc. pour l'etude du Quarternaire: 3-12; Paris.

FrenZel, B. (1977): Postglaziale Klimaschwankungen im südwestlichen Mitteleuropa. - Erdwiss. Forschung, 13: 297-322; Wiesbaden.

FUHRMANN, R. (1976): Die stratigraphische Stellung der Lösse in Mittel- und Westsachsen. - Zeitschr. geol. Wiss., 4: 1241-1270; Berlin.
FunRmanN, R. (1989): Die stratigraphische Stellung des Interglazials von Grabschütz (Kreis Delitzsch) und die Gliederung des Saale-Komplexes. - Zeitschr. geol. Wiss., 17: 1002-1004.

GRAHMANN, R. (1924): Erläuterungen zur Geologischen Spezialkarte von Sachsen, Blatt 48/39, Pegau-Predel nebst Hemmendorf. 2. Auflage. - 34 S.; Leipzig.

HÄNDEL, D. (1967): Das Holozän in den nordwestsächsischen Flußauen. - Hercynia, N.F., 4: 152-198; Leizig.

- (1982): Zur Problematik holozäner Flußschotter. Zeitschr. geol. Wiss., 10: 811-825; Berlin.

JONG, A. F. M. DE \& MOONK, W. G. (1980): Medium-term atmospheric ${ }^{14} \mathrm{C}$ variations. - Radiocarbon, 22: $267-$ 272; New Haven.

KOZARSKI, S. (1983): River channel changes in the middle reach of the Warta Valley, great Poland Lowland. Quarternary Studies in Poland, 4: 159-169; Warszawa/Poznan.

LIEBEROTH, I. (1963) : Lößsedimentation und Bodenbildung während des Pleistozäns in Sachsen. - Geologie, 12: 149-187; Berlin.

LIPPS, S. (1988): Fluviatile Dynamik im Mittelwesertal während des Spätglazials und Holozäns. - Eiszeitalter u. Gegenwart, 38: 78-86; Hannover.

— \& CASPERS, G. (1990): Spätglazial und Holozän auf der Stolzenauer Terrasse im Mittelwesertal. - Eiszeitalter u. Gegenwart, 40: 111-119; Hannover.

LITT, T. (1988): Stratigraphische Belege für anthropogen ausgelöste Bodenverlagerungen vom Neolithikum bis zur frühen Eisenzeit im circumherynen Raum. Ethnographisch-Archäol. Zeitschr., 29: 129-137; Berlin.

-, KOHL, G., GÖRSDORF, J. \& JÄGER, K.-D. (1987): Zur Datierung begrabener Böden in holozänen Ablagerungsfolgen. - Jschr. mitteldt. Vorgesch., 70: 177189; Berlin.

LƯTTIG, G. (1960): Zur Gliederung des Auelehms im Flußgebiet der Weser. - Eiszeitalter u. Gegenwart, 11: 39-50; Öhringen.

MƯler, A. (1988): Das Quartär im mittleren Elbegebiet zwischen Riesa und Dessau. - Diss. Martin-LutherUniv.; Halle.

-, Ortmann, R. \& Eissmann, L. (1988): Die Schwerminerale im fluviatilen Quartär des mittleren SaaleElbe-Gebietes. - Altenburger naturwiss. Forschungen, 4: 70 S.; Altenburg.

SCHIRMER, W. (1983): Die Talentwicklung am Main und Regnitz seit dem Hochwürm. - Geol. Jb., A 71: 1143; Hannover. 
SchmidT, B. (1981): Zur Westgruppe der Lausitzer Kultur. Stuiver, M. \& PeArson, G. W. (1986): High-Precision - Arbeits- und Forschungsber. zur sächsischen Boden- Calibration of the Radiocarbon Time Scale, AD 1950 denkmalpflege, Beiheft, 16: 285-297; Berlin. $\quad-500$ BC. - Radiocarbon, 28, No. 2B, Calibration

Starik, J. E., Arslanov, A. C. \& Kleiner, J. R. (1963): Ulucenija metodika chimiceskoj podgotovki obrazvov SWAART, E. R. (1964): The direct conversion of wood dlja datirovanija po radiouglerodu scintilljacionnym charcoal to lithium carbide in the production of acemetodom. - Radiochimija, 5: 198-205; Moskau. tylene for radiocarbon dating. - Experientia, 20: 47-

StraUTZ, W. (1962): Auelehmbildung und -gliederung im 48; Basel.

Weser- und Leinetal mit vergleichenden Zeitbestim- Wolf, L. (1978): Zum Alter und zur Gliederung der mungen aus dem Flußgebiet der Elbe. - Beitr. Landes- „Döbelner Quartärfolge”. - Zeitschr. geol. Wiss., pflege, 1: 273-314; Stuttgart. 6: 1231-1243; Berlin.

STUIVER, M. (1978): Atmospheric carbon dioxide and carbon reservoir changes. - Science, 199: 253-258; Washington.

Manuskript eingegangen am 20.07. 1990 